(c) Copyright 2020 American Meteorological Society (AMS). For permission to reuse any portion of this work, please contact permissions@ametsoc.org. Any use of material in this work that is determined to be "fair use" under Section 107 of the U.S. Copyright Act (17 U.S. Code §?107) or that satisfies the conditions specified in Section 108 of the U.S. Copyright Act (17 USC $\S 108$ ) does not require the AMS's permission. Republication, systematic reproduction, posting in electronic form, such as on a website or in a searchable database, or other uses of this material, except as exempted by the above statement, requires written permission or a license from the AMS. All AMS journals and monograph publications are registered with the Copyright Clearance Center (https://www.copyright.com). Additional details are provided in the AMS Copyright Policy statement, available on the AMS website (https://www.ametsoc.org/

\title{
Why Are Radar Data so Difficult to Assimilate Skillfully?
}

\author{
FRÉDÉRIC FABRY AND VÉRONIQUE MEUNIER
}

McGill University, Montreal, Québec, Canada

(Manuscript received 12 November 2019, in final form 9 March 2020)

\begin{abstract}
Although radar is our most useful tool for monitoring severe weather, the benefits of assimilating its data are often short lived. To understand why, we documented the assimilation requirements, the data characteristics, and the common practices that could hinder optimum data assimilation by traditional approaches. Within storms, radars provide dense measurements of a few highly variable storm outcomes (precipitation and wind) in atmospherically unstable conditions. However, statistical relationships between errors of observed and unobserved quantities often become nonlinear because the errors in these areas tend to become large rapidly. Beyond precipitating areas lie large regions for which radars provide limited new information, yet whose properties will soon shape the outcome of future storms. For those areas, any innovation must consequently be projected from sometimes distant precipitating areas. Thus, radar data assimilation must contend with a double need at odds with many traditional assimilation implementations: correcting in-storm properties with complex errors while projecting information at unusually far distances outside precipitating areas. To further complicate the issue, other data properties and practices, such as assimilating reflectivity in logarithmic units, are not optimal to correct all state variables. Therefore, many characteristics of radar measurements and common practices of their assimilation are incompatible with necessary conditions for successful data assimilation. Facing these dataset-specific challenges may force us to consider new approaches that use the available information differently.
\end{abstract}

\section{Motivation: Unsatisfactory benefits}

Radar is our best instrument to monitor and study storms; data assimilation is our best approach to combine information from different sources; numerical weather prediction is our best forecasting tool: Given these, one would expect that the assimilation of radar data into convective-scale models should provide the best storm forecasts. Yet, for example to forecast precipitation, simple extrapolations of rainfall patterns often beat numerical forecasting with radar data assimilation in the first 2 or $3 \mathrm{~h}$ (Fig. 1).

There is no denying that radar data assimilation helps to improve NWP forecasts (e.g., Dowell et al. 2011; Jones et al. 2015; and references therein), may it be thanks to variational or ensemble-based assimilation or via latent heat nudging. But if these forecasts do not perform significantly better than the extrapolation of echo movement, they are not as good and useful as one should expect, particularly in the context of storm-scale forecasting. If we examine forecast performance, we

Corresponding author: Frédéric Fabry, frederic.fabry@mcgill.ca note that the skill of NWP aided by radar data assimilation often drops very rapidly in the first forecast hour (e.g., Fig. 1, or Fig. 10 of Aksoy et al. 2010) and/or does not have great skill immediately after assimilation (e.g., Fig. 15 of Mandapaka et al. 2012 or Fig. 8 of Supinie et al. 2017).

This very rapid drop in skill suggests that radar data assimilation may not perform as well as would be expected given its use for weather surveillance. This is problematic given that we intend to largely rely on radar data assimilation to warn for storms on forecasts using numerical weather forecasting approaches (e.g., Stensrud et al. 2009, 2013). Understanding what makes radar data assimilation difficult is hence critical. Some of the problems have been associated with spinup issues as explained by Kalnay and Yang (2010); others may be of a more fundamental nature (e.g., Errico et al. 2007). The question we sought to answer was: What seems to make the assimilation of radar data challenging, particularly in the context of convective-scale forecasting? Note that this question is different and complementary to the more traditional "what makes convective-scale assimilation difficult" for which we already have many answers (e.g., Yano et al. 2018). Since no simple experiment can be 


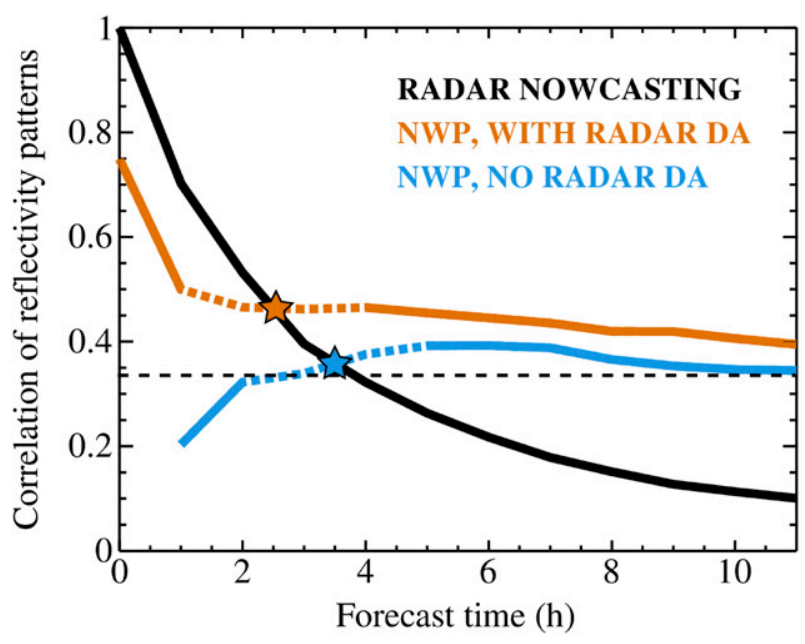

FIG. 1. Skill of the forecast of precipitation patterns made by three systems: the storm-scale ensemble forecasting system run by the Center for the Analysis and Prediction of Storms during NOAA's 2008 Hazardous Weather Testbed (HWT) Spring Experiment (Xue et al.2008) without radar data assimilation (in cyan), the same system with radar data assimilation (in orange), and the McGill Algorithm of Precipitation Forecasting by Lagrangian Extrapolation (MAPLE; Germann and Zawadzki 2002; in black). Note the rapid initial decrease in skill of the NWP forecast with radar data assimilation. [The image is provided through the courtesy of M. Surcel and is based on the work of Surcel et al. (2015).]

devised to answer the question at hand, a reasoning-based approach is adopted. The subject of our reflection will hence follow this axis: What could go wrong and why?

We shall accept as a starting hypothesis that data assimilation generally works, based on existing evidence from its everyday use in operational forecast centers (e.g., Kwon et al. 2018). Given this hypothesis, the challenges of radar data assimilation must come from radar-related specificities, namely the context and conditions under which radar data assimilation is generally performed, peculiarities of the radar data themselves, and how radar data mesh with the assimilation process. To understand what could go wrong, we must first collect the many puzzle pieces before we try putting them together; this involves documenting the characteristics of the data being assimilated, and highlighting peculiarities that may cause difficulties. Issues arising from the interaction between these peculiarities and the assimilation machine will be subsequently investigated, sometimes numerically, sometimes using more qualitative reasoning, to expose what may affect the quality of either the analysis or the forecast resulting from the assimilation.

\section{Context of assimilation and nature of radar data}

The assimilation algorithm operates on data that have specific characteristics and error properties. Let us first focus on the characteristics of the background information and of the data at the meso and convective scales where radar data assimilation is generally being performed.

\section{a. Quality of a priori information}

Many mesoscale and convective-scale assimilation efforts start with background information originating from a global model analysis. These analyses are already based on the assimilation of data from a wide range of instruments. In such setups, smaller-scale data assimilation systems then take this background and add unused denser data such as from radars, satellite imagers, and in situ measurements from aircrafts and surface stations (e.g., Benjamin et al. 2016).

What is the uncertainty of the global analysis used as background? This is not well known, especially at the smaller scales relevant to convective storms. To get a first-order estimate of that uncertainty, we chose to look at the mismatch between the analyses of the control member of ensemble forecast systems from many global prediction centers: If all analyses from control members are similar, there is a good chance they are close to accurate, though this is not certain; if they disagree, they are likely all wrong. On that basis, the average difference between these analyses probably represents a lowerbound estimate on their expected uncertainty.

Using data from the THORPEX Interactive Grand Global Ensemble (TIGGE; Bougeault et al. 2010), the analyses of many global centers were compared for June and July 2018 in the midlatitudes of the Northern Hemisphere. The results of that comparison for key atmospheric properties shaping convective storms (Fig. 2) suggest that their structure is well captured at scales larger than $1000 \mathrm{~km}$ but is poorly known at scales smaller than $500 \mathrm{~km}$ in summer, largely irrespective of the atmospheric property considered. Hence, correct mesoscale structures must be rebuilt from either surface forcing (higher-resolution orography, surface properties, land-use and vegetation cover), the assimilation of additional information, or arising processes at smaller scales. Because larger mesoscale structures evolve more slowly than smaller entities, such as individual convective cells, they provide skill to longer lead-time forecasts. Hence, failing to rebuild mesoscale structures in addition to the storm-scale structures will limit the lead time of useful storm-scale forecasts. If data assimilation cannot rebuild both cells and larger-scale structures $(10-1000 \mathrm{~km})$, forecasts will suffer.

\section{b. Data density considerations}

What data are available to rebuild those structures, particularly at scales relevant to convection? Table 1 lists the number of measurements available over the typical scale $(10 \mathrm{~km} \times 10 \mathrm{~km})$ and lifetime $(1 \mathrm{~h})$ of a storm cell. 
a) Spectral decomposition of the ECMWF control

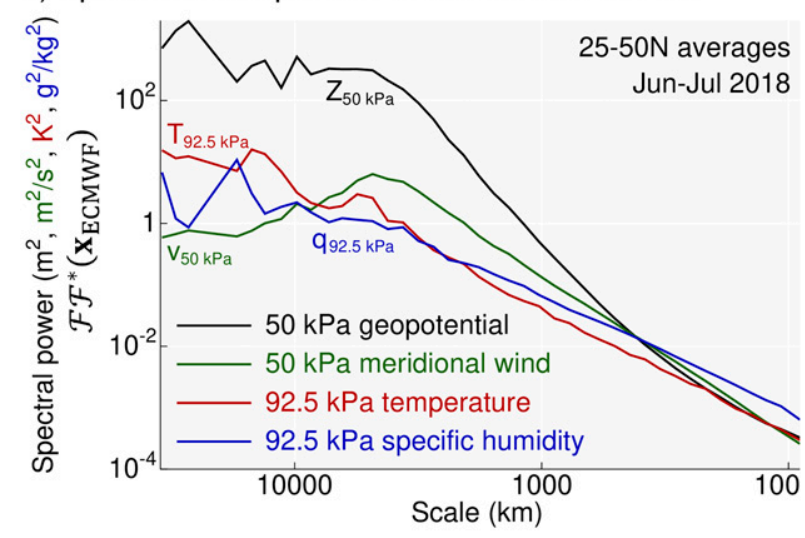

b) Control-to-control inconsistency in spectral variability

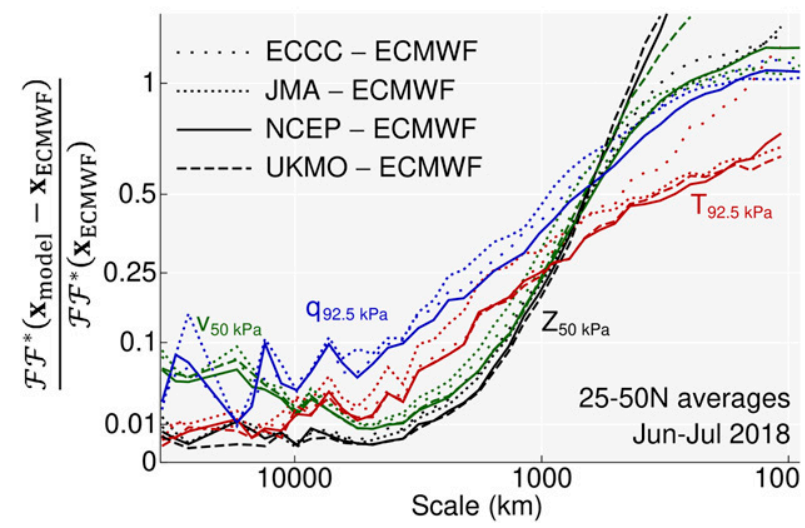

FIG. 2. (a) Spectral decomposition of 50-kPa geopotential height (black), 50-kPa meridional wind (green), 92.5-kPa temperature (red), and $92.5-\mathrm{kPa}$ specific humidity (blue) along lines of constant latitude and averaged over $25^{\circ}-50^{\circ} \mathrm{N}$ in June and July 2018 for the analysis of the control member of the ECMWF ensemble system. Except at small scales, curves for control members of other global ensemble systems are very similar. (b) Ratio of the average spectral decomposition of differences between control members in the numerator and the average spectral decomposition of the ECMWF control in the denominator, for the same atmospheric properties as in (a). Ratios of 0 imply that the two control members being considered are identical at that scale, whereas ratios of 1 arise when the magnitude of control-tocontrol differences are comparable to that of the patterns in the ECMWF control. For each of the four properties listed above, four curves illustrate the relative difference between ECMWF controls and those of four other centers: the Environment and Climate Change Canada (ECCC; spaced dotted lines), the Japan Meteorological Agency (JMA; tightly dotted lines), the National Centers for Environmental Prediction (NCEP; solid line), and the Met Office (UKMO; dashed lines). For all considered properties and analysis pairs, considerable inconsistencies exist at scales below $500 \mathrm{~km}$, much larger than the resolution of all of the models considered.

Supposing that independent data are available at roughly 1-km resolution over 20 elevation angles and are measured every $5 \mathrm{~min}$, radar provides approximately 25000 measurements of reflectivity and a somewhat smaller number (say, 15000) of valid Doppler velocity measurements. Except for satellite data, nothing comes close to the density of radar information: as illustrated in Table 1, rare are the constraints from other data sources in the context of the scale and lifetime of a convective cell. In that situation, it will hence largely be the responsibility of radar data to correct for the missing or erroneous information of the background at scales smaller than a few hundred kilometers in between available sounding data.

But are 25000 reflectivity and 15000 radial velocity constraints over the lifetime of a convective cell a little or a lot? For reference, in the 1980s, we primarily relied on radiosonde measurements to forecast synoptic-scale systems. For a typical $2000-\mathrm{km}$ storm lasting 5 days, the information used from about 40 stations (one every $315 \mathrm{~km}$ in the continental United States) launching radiosondes twice per day consisted of four measurements (temperature, humidity, and two wind components) at eight mandatory levels up to $20 \mathrm{kPa}$, or 12800 direct constraints. Because at these scales one can benefit from hydrostatic and quasigeostrophic balance to some extent, and if we also add surface stations, the actual total number of constraints on atmospheric fields probably approached 20000 . Hence, the number of constraints obtained by a radar on a convective cell is of the same order of magnitude as what was available in the 1980s to forecast synoptic-scale systems. There are, however, two key differences: First, whereas the data from radiosonde covered most key dynamic and thermodynamic fields, the data from radar are largely limited to precipitation and one wind component. Second, outside stormy areas, the information provided by radar largely collapses to "no measurable echo", an information nevertheless precious to suppress precipitation.

An interesting sidebar is that in the 1980 s, with the data provided by radiosondes, one could usefully forecast synoptic-scale storms over a period of 5 days, which roughly corresponds to the lifetime of the event itself. If the same logic applies for thunderstorms, one can at best hope to reasonably forecast the outcome of $10-\mathrm{km}$ scale structures like convective cells for about their 1-h lifetime (see Fig. 9 of Sun et al. 2014) with the data that are currently available. Although this simplistic comparison ignores issues of predictability and advances in data assimilation and modeling, it suggests a sobering limit to what could ultimately be achieved with convective storm forecasting without additional data constraints, one that is partly corroborated by predictability studies at the convective scale (e.g., Fig. 5 of Surcel et al. 2015).

\section{c. Operationally available radar data}

\section{1) THE INFORMATION FROM REFLECTIVITY}

Let us now focus on the nature of the information provided by radar, starting with reflectivity. The intensity 
TABLE 1. Measurements of any atmospheric variable per hour over a $10 \mathrm{~km} \times 10 \mathrm{~km}$ area comparable to the size of a convective cell. For this exercise, a typical surface station reports information for five variables (pressure, temperature, dewpoint, winds, and precipitation).

\begin{tabular}{ll}
\hline \hline \multicolumn{1}{c}{ Data source } & No. of observations \\
\hline Upper-air observation of any variable using planes, & \\
$\quad$ radiosondes, global navigation satellite system receivers, etc. & $\approx 0-10$ (highly variable) \\
$\begin{array}{l}\text { Surface observations of any variable } \\
\text { Geostationary satellite (per thermal IR channel) }\end{array}$ & $\approx 0-10$ (highly variable) \\
& $\approx 1200$ (largely limited to altitudes from cloud \\
Radar reflectivity & top upward in the presence of clouds) \\
Radial velocity (assuming $60 \%$ echo coverage in storms) & $\approx 25000$ \\
\hline
\end{tabular}

of the radar echo at traditional surveillance radar wavelengths is mainly dictated by the number and size of the largest hydrometeors, as reflectivity largely depends on the sixth moment of the hydrometeor size distribution [e.g., $Z=\int N(D) D^{6}$ in rain]. Radars have a range-dependent minimum sensitivity below which "no measurable echo" is reported. In the absence of significant beam blockage or attenuation, that threshold is such that most solid and liquid precipitation are observed by weather surveillance radars, but liquid clouds and many ice clouds are not. Reflectivity, or the sixth moment of the drop size distribution, is generally not a modeled quantity. In the process of simulating radar observations, the assimilation system must convert the moments simulated by models such as precipitation mixing ratio into reflectivity, a process not unlike what radar meteorologists do when converting reflectivity $Z$ to rainfall rate $R$ using $Z-R$ relationships. It must also do so accounting for the geometry of radar measurements. Since the mass-to-reflectivity conversion cannot be done perfectly, errors that are correlated in space will result (e.g., Fig. 1c of Lee et al. 2007). For example, the same microphysical processes that cause drops to be unusually large or small for a given precipitation rate at one location also act in nearby areas. In the 70 years we have had $Z-R$ relationships, we have not definitely characterized the statistical properties of their error, especially their spatial error covariance. This characterization must now be achieved to help data assimilation, and this error must be included in the observational term error as it reflects a basic uncertainty of the observation operator. Yet, at this time, it is largely assumed to be uncorrelated in assimilation systems. These correlated errors will generally dwarf accepted measurement errors (Keeler and Ellis 2000) unless the radar is not properly calibrated.

More important is the spatial structure of the precipitation field sampled by radar reflectivity measurements. Meteorologically, precipitation is an intermittent doublethreshold process: first, clouds occur when saturation is reached, primarily in updrafts; then, precipitation grows only when enough cloud droplets are present. As a result, it is sparse, covering only a few percent of the United States on average in summer, and also much more structured at small scales than other atmospheric fields (Fig. 3), except perhaps vertical velocity. The consequences of the unusual topology of precipitation fields on assimilation will be examined in section 3 . The relatively high structure of precipitation at small scales combined with the lower quality of background information at scales below $500 \mathrm{~km}$ (Fig. 2) cause precipitation background errors to be generally larger in magnitude and have shorter correlation distances than those of other fields. This will have consequences on the effectiveness of radar data assimilation (section 3d).

In addition, radar cannot accurately measure reflectivity under some circumstances, particularly when echoes from hydrometeors are too weak or contaminated by other echoes. In such situations, "no measurable weather echo" is generally reported. We often take a shortcut and assume that this means "zero reflectivity". Complications arise when we assimilate logarithmic reflectivity ( $\mathrm{dBZ}$ ), as a value of minus infinity ensues. Since $-\infty$ cannot be used numerically, this problem is solved by setting all reflectivity values below a certain threshold to an arbitrary value such as 5 or $10 \mathrm{dBZ}$ (e.g., Tong and Xue 2005; Gastaldo et al. 2018). This choice also conveniently eliminates many weak nonmeteorological echoes. Ignoring the consequences of this choice, one should realize that, fundamentally, the information being reported by radar is not "zero reflectivity" but instead "reflectivity is below a threshold". In the absence of attenuation or beam blockage, that threshold $Z_{\min }$ simply depends on radar characteristics and range. For example, on WSR-88D instruments in precipitation mode, it is approximately $20 \log _{10}(r)-40 \mathrm{dBZ}$, where $r$ is the range to the target in kilometers. Sometimes, echoes were initially present but were later suppressed because they were deemed to be primarily from nonweather targets such as insects or 


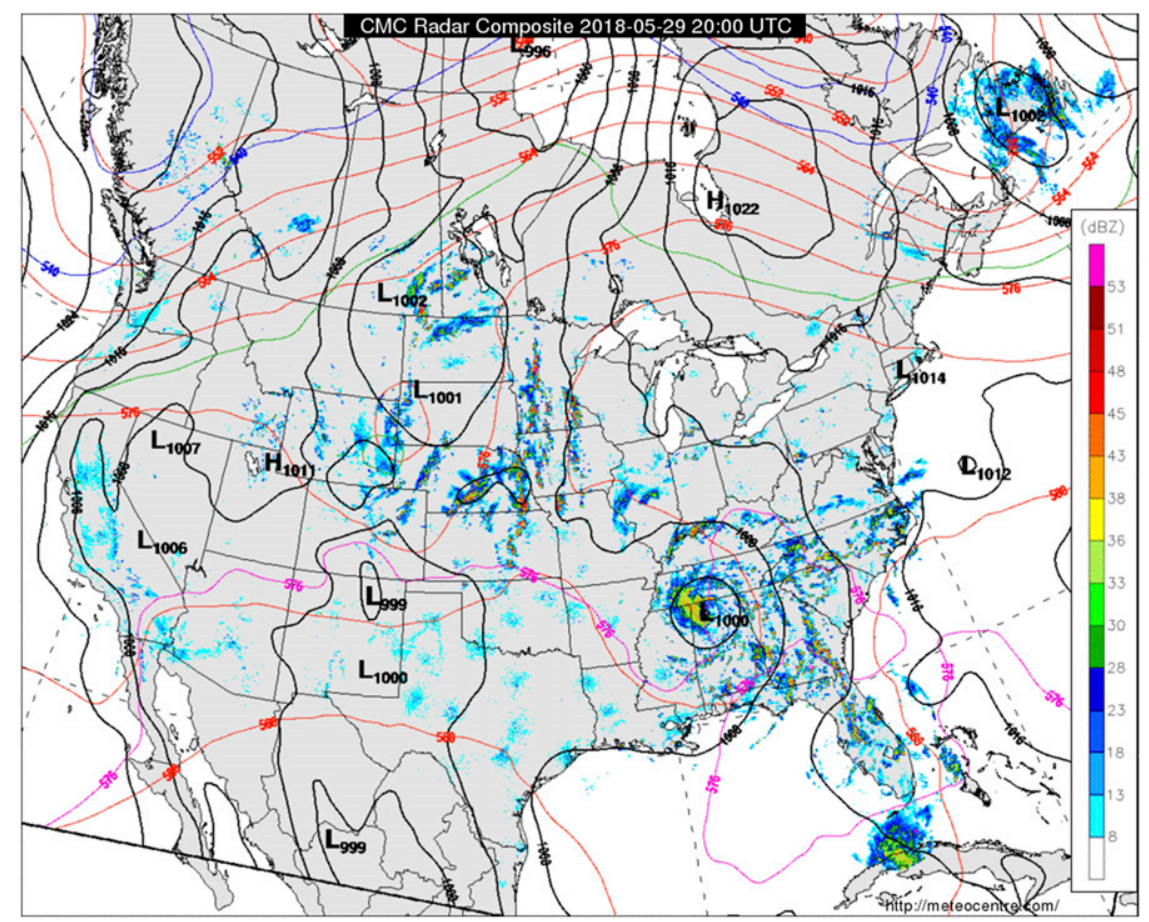

FIG. 3. Composite of reflectivity from Canadian and U.S. radars on a late-spring afternoon on which are overlaid black contours of sea level pressure, red contours of constant 50-kPa heights, and purple contours of constant $100-50-\mathrm{kPa}$ thicknesses. Contrast the spottiness of reflectivity with the smoothness of pressure, reflecting the strong variability at small scales and the weak variability at large scales of precipitation fields. (The image is provided through the courtesy of the Canadian Meteorological Centre and meteocentre.com.)

the surface. In that case, all we know is that any possible weather echo is less intense than that of the contaminating echo. These two examples illustrate the lack of specificity of the "reflectivity is below a threshold" information and how it does not equate to "zero reflectivity."

\section{2) REFLECTIVITY UNITS AND VALUES}

Radars are generally able to detect equivalent reflectivity factors $Z_{e}$ ranging from less than 0.1 to more than $10000000 \mathrm{~mm}^{6} \mathrm{~m}^{-3}$. For a variety of largely historical, technical, and practical reasons, logarithmic, or decibel, units [ $\mathrm{dB} Z$, or $\left.10 \times \log _{10}\left(Z_{e}\right)\right]$ are generally used to archive and display reflectivity values. In addition, the distribution of reflectivity values from precipitation is unusual (top of Fig. 4): whereas, at any given height, most atmospheric fields generally have a quasi-symmetric distribution around an average, precipitation intensity and its equivalent radar reflectivity factor $Z_{e}$ have distributions that follow more closely exponentials with a delta function added at zero precipitation. In that context, using $\mathrm{dB} Z$ values for reflectivity has a potentially interesting property: the distribution of $10 \times \log _{10}\left(Z_{e}\right)$ values is closer to a normal distribution (bottom of Fig. 4), and so, it is hoped, would the distribution of their errors. For all of these reasons, reflectivity values in $\mathrm{dB} Z$ units are generally assimilated. The wisdom behind this choice will be examined in section $4 \mathrm{a}(1)$.

\section{3) THE "MEAN" DOPPLER VELOCITY INFORMATION}

The mean Doppler velocity is an estimate of the radial component of target velocity with respect to the radar. Its measurement is only available in the presence of echoes, may those be from weather or from nonmeteorological targets. In many ways, it is easier to assimilate than reflectivity as it does not suffer from calibration or attenuation bias, and it is more directly related to model state variables. It is also the only direct constraint obtained concerning storm dynamics by radar, complementing satellite-derived information. Consequently, most researchers find that radial velocity assimilation helps improve forecasts, as a result of which Doppler data are assimilated by many operational centers (Gustafsson et al. 2018).

Doppler velocity assimilation is, however, not free of problems. Target velocity is largely wind velocity plus fall velocity which can be significant for rain. It can be 


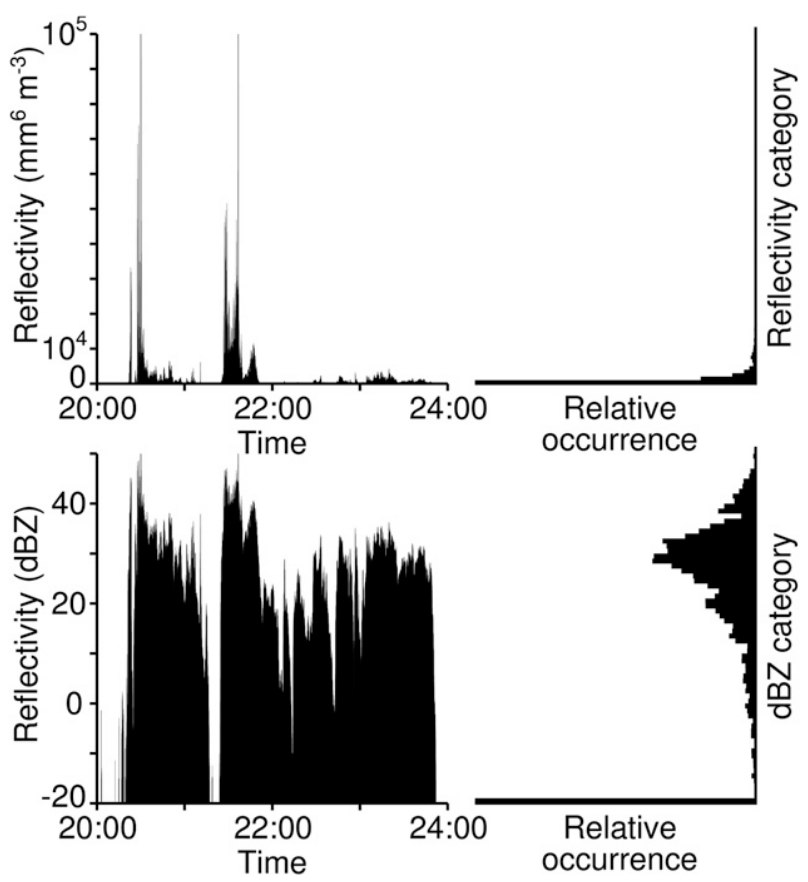

FIG. 4. Time series of reflectivity at one location from a rain event plotted using (top) linear and (bottom) logarithmic reflectivity scales. On the right, the associated histograms of occurrence of different reflectivity are plotted sideways to match the reflectivity values on the left of the plot. Histograms of reflectivity generally resemble exponentials, whereas those of logarithm of reflectivity look more like normal distributions to which are added a second peak for reflectivity values corresponding to "no echo." [The figure is adapted from Fabry (2015).]

contaminated by surface clutter, birds, and insects, though this contamination is diminishing with improved radar signal processing. Under some circumstances, it can be aliased. The simulation of its measurement geometry is often too simplified (Fabry 2010). Lesser known is that the signal-processing algorithms estimating mean Doppler velocity are biased when the distribution of radial velocities is nonsymmetric [e.g., our Fig. 5, or Eq. (4.5) of Zrnić 1979]. And while perfect operators such as Eq. (9) of Fabry (2010) can handle these situations, they are too complicated to be usable. This leads to errors correlated in space that then result in artificial convergence or divergence patterns as the slowly elevating beam gradually traverses regions of vertical wind shear.

\section{4) DUAL-POLARIZATION INFORMATION}

The increasing availability of dual-polarization radars is stimulating research on the assimilation of their data (Li et al. 2017; Augros et al. 2018; and references therein). Dual-polarization measurements, such as specific differential phase $K_{\mathrm{DP}}$, differential reflectivity $Z_{\mathrm{DR}}$, and copolar correlation coefficient $\rho_{\mathrm{HV}}$, provide

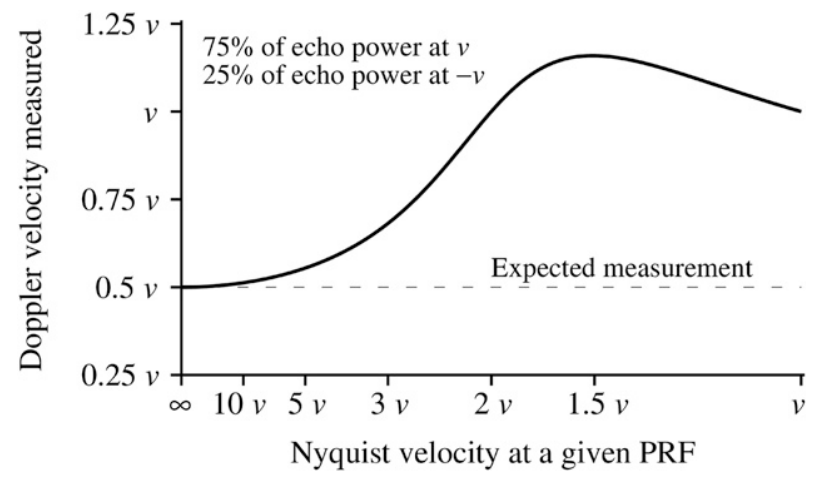

FIG. 5. Mean Doppler velocity estimated by a radar as a function of Nyquist velocity when $75 \%$ of the received echo power comes with a radial velocity $v$ and $25 \%$ with a radial velocity $-v$. Using common sense and all currently used observation operators, one would expect a measurement of $v / 2$, but this result is not what standard radar signal-processing algorithms such as pulse pair or Fourier transform "on a circle" (Keeler and Passarelli 1990) return as result. Note that the Nyquist velocity considered here is the raw one from a single pulse repetition frequency (PRF) and not the combined value arising from the use of multiple PRFs.

constraints on precipitation mass, mean target shape and its variability. Measurements or retrieved properties can then be assimilated to improve precipitation simulation. While some benefits are observed in rain, the unknown and complex relationship between modelsimulated properties such as hydrometeor type, number, and mixing ratio, and radar observations in ice remains an obstacle (e.g., Posselt et al. 2015).

\section{d. Summarizing the assimilation context}

Relative to measurements from many other instruments, radar data are more challenging to interpret: Reflectivity is a measure of higher moments of the hydrometeor size distribution than are generally modeled numerically; its estimate for weak and contaminated values is poor and ambiguous to interpret; Doppler velocity can be biased; polarization signals are weak and difficult to simulate; and last but not least, the errors on measurements and their simulation are not well quantified and their spatiotemporal correlation not well known. By themselves, these issues would make radar data assimilation difficult. But they are probably minor when compared with what follows.

\section{Arising issues with assimilation}

\section{a. Challenges modeling precipitation at smaller scales}

As illustrated in Fig. 3, precipitation has considerably more small-scale variability than other fields. The associated mismatch between real and simulated reflectivity observations will hence be dominated by 
small-scale patterns. Therefore, for assimilation systems to use the innovation from such observations, models must be able to properly simulate smaller-scale processes. Yet, this is difficult to achieve properly because of limited resolution and microphysics. If a model is not able to reproduce an observation for the correct meteorological reasons, the assimilation of such an observation is unlikely to lead to the proper correction of model fields. Consequently, the benefits of the innovation from precipitation observations are reduced. This is in addition to the fact that, at high resolution, innovations can be very large, for example if there is a spatial mismatch between simulated and observed precipitation. A case could be made that perhaps we should not assimilate measurements at the highest available resolution since models cannot simulate the finest-scale processes of precipitation shaping what radars measure. Determining what better observational constraint to provide could lead to improved effectiveness of radar data assimilation.

\section{b. Relevance of the measured information}

Radar has become a valued operational instrument for weather surveillance because of its ability to characterize storms and monitor their impacts. Therefore, we naturally think that its data should be equally skillful at helping us forecast these storms numerically. But radar is much better at detecting the outcomes of storms than at inferring their causes. In fact, radars detect precipitating cells relatively late in their life cycle. Consider the textbook evolution of convective cells: Storms begin thanks to the combination of environment conditions that provide its fuel (temperature and humidity profiles), and a forcing mechanism that breaks the capping inversion preventing the storm to form earlier (e.g., via low-level convergence). Except sometimes for the forcing mechanism itself, radar is largely blind to these environmental conditions. As the unstable air parcel accelerates upward, clouds form rapidly. But again, radar is largely blind to water clouds. Only when coalescence or ice crystal growth is significant enough do echoes appear aloft as illustrated by first echo studies (e.g., Knight et al. 1983) and numerical modeling of storms cells (e.g., Fig. 2 of Murakami 1990). It is at the latter stages of storm evolution that radar provides its best information. Unfortunately, this does not give us much time to use radar information to make a valuable numerical forecast for that cell. Note that the late appearance of precipitation during the release of an atmospheric instability is not limited to convective processes but is also the case for baroclinic systems.

We can complement the time-evolution view above with information obtained by considering atmospheric evolution in a process-oriented context. The box-andarrow diagram in Fig. 6 illustrates the many interactions between different atmospheric properties relevant to weather forecasting. As mentioned before, radars measure precipitation properties, and one component of the 3D wind where echoes are available. But the main driving force of storm dynamics is the pressure gradient arising from temperature and/or density contrasts, while the main control on storm intensity is low-level temperature and humidity. And though the dynamical and thermodynamic components of atmospheric motion are tightly coupled (top of Fig. 6), the water cycle largely follows one large loop whose last atmospheric component is precipitation (bottom of Fig. 6). In fact, the property best constrained by radar measurements, precipitation, 1) is the farthest from storm drivers yet 2) is short lived without them, reducing its interactions with other fields. Indeed, if precipitation is modified in a model analysis and nothing else, that precipitation will fall out quickly without having had much time to influence the evolution of other atmospheric properties except through drag and evaporation. Only if assimilation properly changes the fields that cause precipitation may it have a lasting positive effect. Perhaps the main exception to the above is when a radar observation of no significant echo invalidates a storm in a model, as suppressing rain and some humidity will generally suffice to hinder storm activity. Indeed, many researchers find that suppressing model precipitation where it does not occur contributes significantly to the skill of radar data assimilation (section 2c of Wattrelot et al. 2014 and references therein). As for Doppler velocity, its coverage is limited to stormy regions that have considerable small-scale structures; innovations from this incomplete constraint to the 3D target velocity have complex relationships with innovations in other fields.

This discussion illustrates two additional challenges of radar data assimilation at convective scales: 1) direct information on storm properties arrive late in the time evolution of storms and 2) the atmospheric fields well measured by radar are remotely connected with those that shape the evolution of present and future events. We must hence largely rely on indirect information-namely, what current storm characteristics can tell us about storm drivers in the past and what we can infer from them concerning storm drivers in the future.

\section{c. Strong need for information projection}

This is where the nature of the precipitation field causes challenges. Over most of the troposphere, precipitation is zero (e.g., Fig. 3). This fact is generally well reproduced by models. In fact, for much of the model grid space, the background and the measurements agree perfectly that echoes are absent. Radar data hence 


\section{Interactions between Dynamical and Thermodynamic Properties Driving Weather Systems}

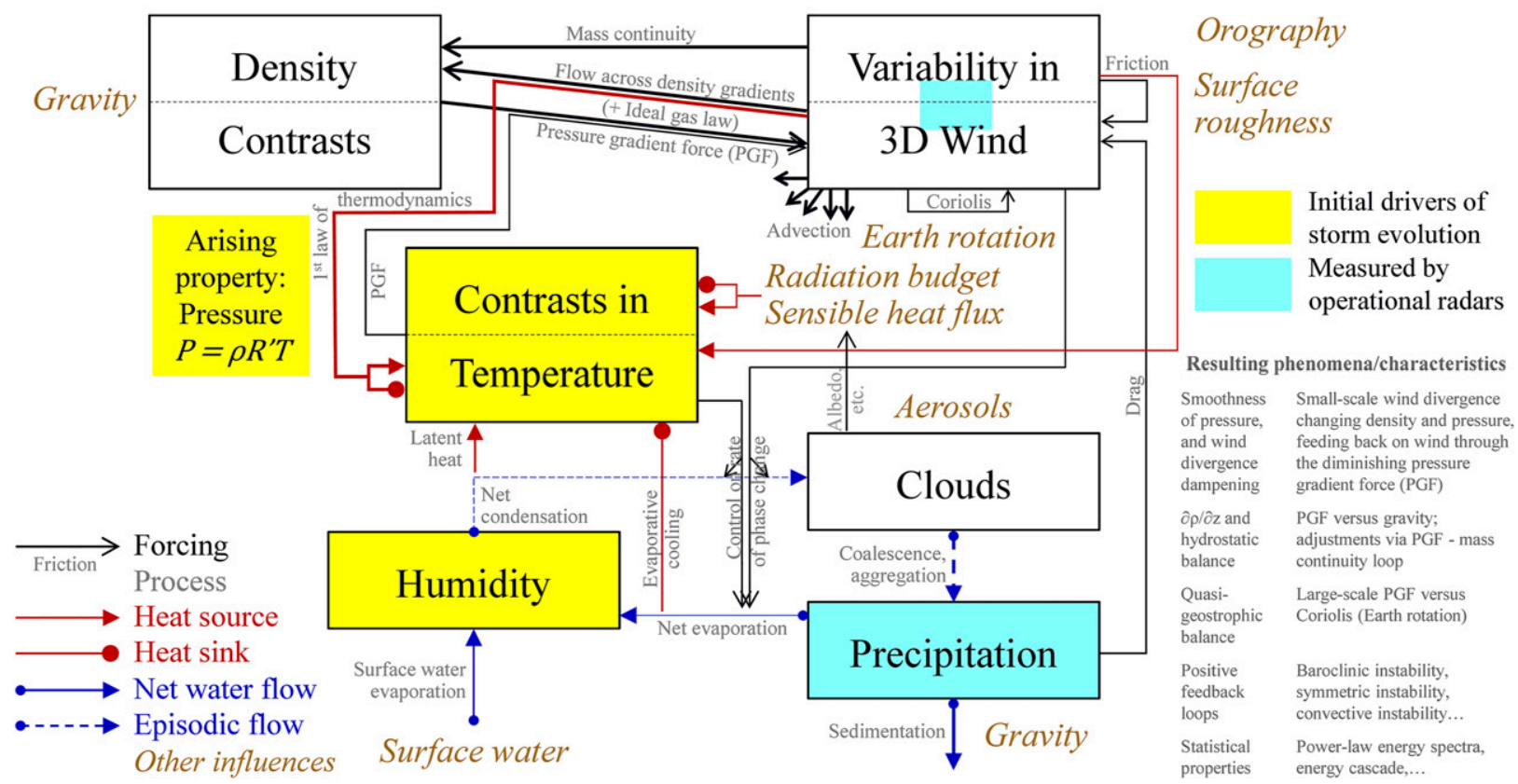

FIG. 6. System diagram illustrating critical interactions between different properties of an evolving atmosphere at scales relevant to weather forecasting. Two interacting subsystems can be identified: the dynamical subsystems (largely in the top of the diagram), in which interactions occur continuously largely through differential equations, and the water cycle (largely in the bottom of the diagram), in which interactions tend to be more episodic. Highlighted elements contrast the initial drivers of storm evolution (in yellow) with properties constrained by radar (in cyan). Phenomena or field characteristics arising from atmospheric interactions are also listed at the bottom right.

provide no innovation in these areas, and there is no reason to modify the background. Observations will induce an innovation only when they disagree with the background, and this occurs only in clustered areas where either the background or observations have precipitation. This limits the spatial extent of innovations introduced by the assimilation of radar data. More important, it leaves large regions unconstrained by radar measurements, including many that will play important roles in the future evolution of weather events.

Consider the tornadic supercell storm in the rounded rectangle in Fig. 7a that struck Tuscaloosa Alabama, in 2011. It is a perfect example of the type of events we want to forecast well in advance, say with a reasonable lead time of an hour. To forecast such a storm, we need to know the inflow that will provide its heat and moisture (identified as the colored letters A and B in Fig. 7b). We also need to know the properties of the air that will make up the surrounding environment and feed the storm's downdrafts (colored letters C-E). An hour before, where is that air? On the basis of the radar-derived wind measurements, it is in the areas bounding the white letters in Fig. 7b. Most of those are devoid of radar echoes; therefore, radar cannot obtain much information about them, at least directly. Note that, in this case, these areas are also covered by high-level clouds, limiting any help that could come from spaceborne imagers.

Therefore, to improve forecasts, there is a critical need for the available information to be projected from innovative precipitating areas out to other regions devoid of new constraints. While this need is always present in data assimilation, it is surprisingly imperative for radar data, given that data density should not be an issue: While data density is indeed high, because of the clustered nature of precipitation areas, there are huge regions where radar measurements do not directly provide information about the background state. We have also seen that there are significant background errors at scales up to hundreds of kilometers (Fig. 2) and gaps between precipitation areas comparable or exceeding such distances (Fig. 3). It is therefore imperative for assimilation systems to project information up to hundreds of kilometers outward to help improve forecasts of a few hours. In Fig. 7b for example, if information obtained from radar data cannot reach the areas labeled with a white $\mathrm{A}$ and $\mathrm{B}$, radar data assimilation cannot be used to improve our knowledge of the properties of the air that will feed the supercell updraft an hour later, which severely limits possible forecast improvement. 

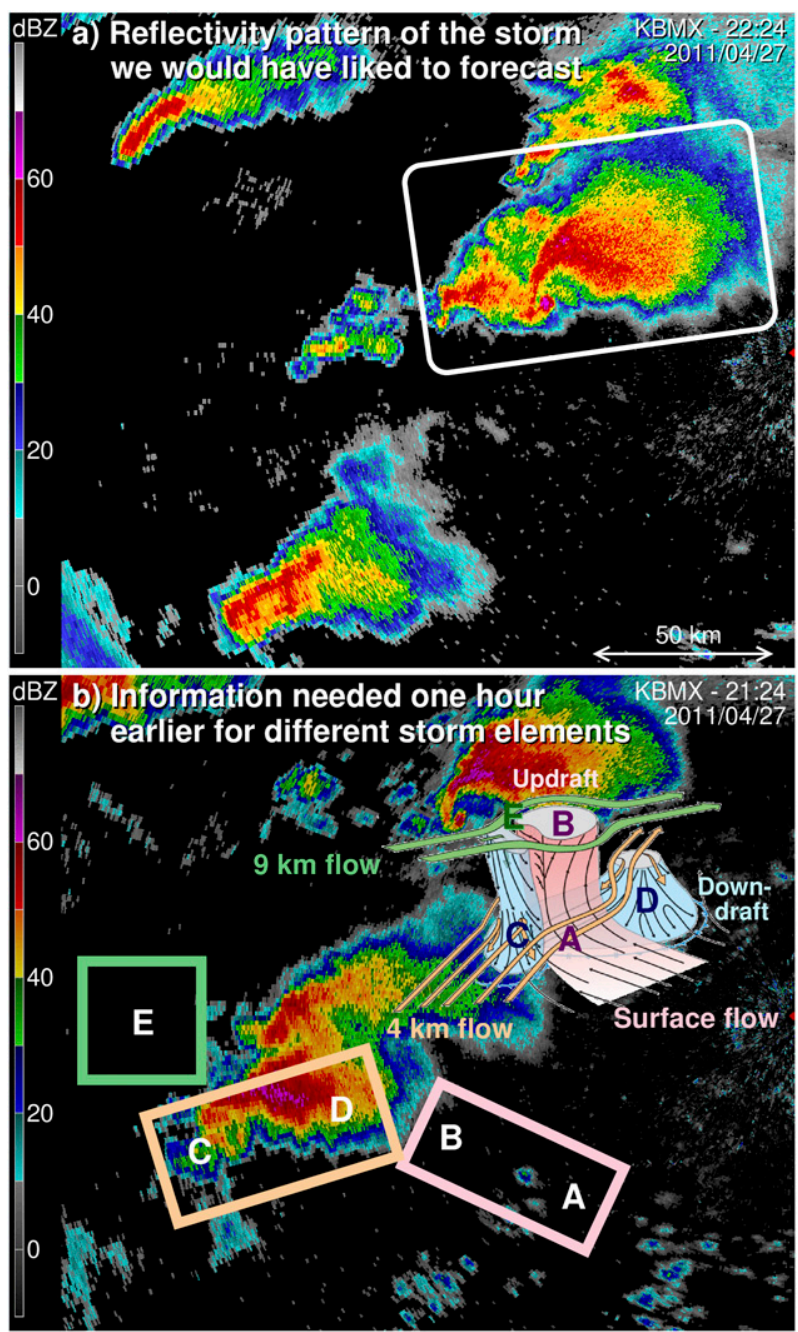

FIG. 7. Example illustrating the limited amount of direct constraints from radar data on areas that will shape the latter evolution of severe events: (a) radar reflectivity image of a tornadic supercell storm at time $t$ that we wanted to forecast at $t-1 \mathrm{~h}$ and (b) composite image of a conceptual diagram of a supercell storm at the position of the storm in (a) and the reflectivity image at $t-1 \mathrm{~h}$. On the diagram, which is provided through the courtesy of Markowski and Richardson (2010), key areas are labeled by colored letters. The air in these areas at time $t$ originates at $t-1 \mathrm{~h}$ from the areas inside the colored rectangles with corresponding white labels. Most of these are in echo-free regions; as a result, the properties of the air in these source areas are unlikely to be directly constrained by radar measurements.

Yet, currently (Table 1) there is no clear alternative data source for that task, especially in cloudy areas.

\section{d. Obstacles to information projection}

The uncertainty on state variables far away from storms can only be reduced if we can devise relationships between values or errors of characteristics of radar echoes (reflectivity, radial velocity, etc.) and values or errors of atmospheric properties well outside echo regions. Usually, these relationships are based on the covariance between errors in observational constraints and errors in state variables. To be useful for assimilation, these relationships must first exist, either physically or statistically, and they must also be either known a priori (like in 3DVar) or determined based on available information (like in ensemble-based approaches).

Unfortunately, precipitation 1) is a delayed outcome of its root causes (section $3 b$ ) and 2) has smaller-scale errors than other fields [section $2 \mathrm{c}(1)$ ], both complicating the relationship between precipitation intensity and other atmospheric properties locally and at larger distances. As a result, the correlation between errors on point precipitation values and on other properties is on average weak (Fig. 8). This is particularly the case at low levels where, by the time the rainfall arrives, the dynamical processes that led to its creation occurred a long time ago. Nonetheless, the correlation $\rho$ between observed quantities and state variables must be strongly positive or strongly negative for effective error reduction: Given a perfect observation, the error on the correlated state variable will be reduced by a fraction $1-\left(1-\rho^{2}\right)^{1 / 2}$ [Eq. (A5) of Jacques et al. (2018)]. As such, correlations of $0.2,0.4,0.6$, and 0.8 will then, respectively, lead to an error reduction of only $2 \%, 8 \%$, $20 \%$, and $40 \%$. If observations have errors, the resulting innovations and error reduction will be even smaller. Since high correlations between precipitation and other state variables are rare, especially at longer distances (Fig. 8), greatly reducing errors on other state variables by assimilating precipitation is difficult.

While the theory of using error covariances to reduce the uncertainty in initial conditions is sound, it is only truly effective if error correlations are high. In the atmosphere, this occurs primarily when errors are small enough to grow linearly, or when considered over short enough time scales that the relationships are approximately linear, and when higher-order error terms or unexpected instabilities have minor consequences. However, generally in precipitation and particularly in convection, instabilities play key roles. In fact, precipitation largely arises as a delayed response from atmospheric instabilities, whether baroclinic, convective, or otherwise. Since radar largely provides information on precipitating areas, that information will hence generally be concentrated in areas where instabilities are being or have recently been released. A resulting challenge is that while background errors might have been small and Gaussian-distributed before the triggering of the instability, this is no longer the case by the time one detects a significant difference between simulated and real radar measurements. 


\section{Correlation between ensemble-simulated errors in reflectivity (dBZ) and in various model state variables}
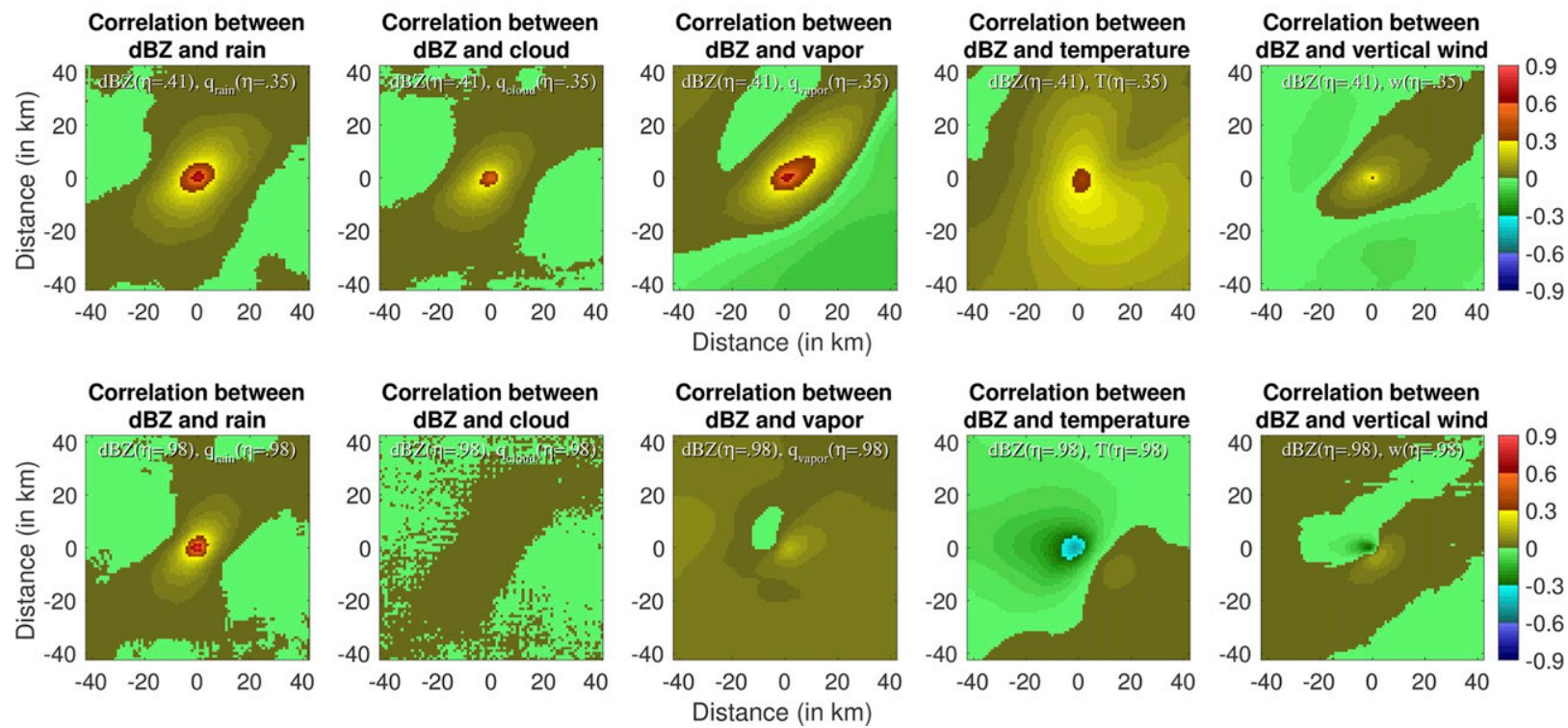

FIG. 8. Average correlation between simulated reflectivity measurements from the ensemble generated by Jacques and Zawadzki (2015) and nearby background state variables of rain mixing ratio $q_{\text {rain }}$, cloud mixing ratio $q_{\text {cloud, }}$ water vapor mixing ratio $q_{\text {vapor }}$, temperature $T$, and vertical velocity $w$ in (top) the upper troposphere and (bottom) the lower boundary layer. These correlations are averages over a $100 \mathrm{~km} \times 100 \mathrm{~km}$ region at one time in an area with scattered showers. In all cases, limited correlation is observed beyond a few kilometers. Reflectivity measurements in the upper troposphere (here at eta level $\eta$ of 0.41 ) can provide some information on uppertropospheric state variables $(\eta=0.35)$, but those in the boundary layer $(\eta=0.98)$ are not as skillful at constraining boundary layer state variables $(\eta=0.98)$. For this calculation, all reflectivity measurements below $10 \mathrm{~dB} Z$ were set to $5 \mathrm{~dB} Z$, and at least one member had to have a reflectivity greater than $10 \mathrm{~dB} Z$ for the resulting correlation matrix to be included in our calculation.

This has a few consequences that affect the potential performance of radar data assimilation positively and negatively: 1) radar provides most of its information in regions where more constraints are badly needed, because precipitation occurs in areas where the atmospheric state is rapidly evolving as a result of an unfolding instability, 2) by its very nature, the rapidly evolving atmosphere in unstable regimes makes any information more difficult to use, especially if that information is limited to a small subset of atmospheric properties as is the case for radar, and 3) contrary to most other data sources, radar provides little information in more stable atmospheric regimes where error reduction could be easier to achieve with incomplete constraints.

\section{e. Resulting forecast}

What will then happen when radar data are assimilated? While observed fields such as precipitation and one wind component will be significantly corrected in the analysis, key unobserved fields such as temperature and humidity will only be marginally updated from the background, and only in or very close to precipitating areas, particularly in an Ensemble Kalman filter context. The storm dynamics and thermodynamics will hence be largely incompatible with the updated precipitation field. When the forecasting model will subsequently be run, after some time, the modified precipitation will have fallen and be replaced by one compatible with other fields; the resulting precipitation field will then largely resemble that of the background. The model will consequently appear to have forgotten the assimilated data, and will return to a trajectory somewhat resembling the one prior to assimilation.

This problem goes beyond the ability to forecast properly a storm in the "distant" future. For example, let us consider what happens when assimilating observations of a burgeoning cell in a background that lacks such convection, but that is otherwise ripe for it. The intimidating Fig. 9 contrasts the evolution of a model cell in a WRF nature run with that of an identical twin model run driven by radar data assimilation; that latter run is one member of a 50-member ensemble constrained by assimilating reflectivity data in an ensemble adjustment Kalman filter (EAKF) framework using the Data Assimilation Research Testbed (DART; Anderson et al. 2009). Focusing first on the nature run, we observe that the growing cell is driven by boundary layer convergence that feeds a growing updraft, saturates air, and generates increasing amounts of precipitation increasingly higher as 


\section{Time sequence of a "real" growing convective cell compared to its modelled/assimilated counterpart}
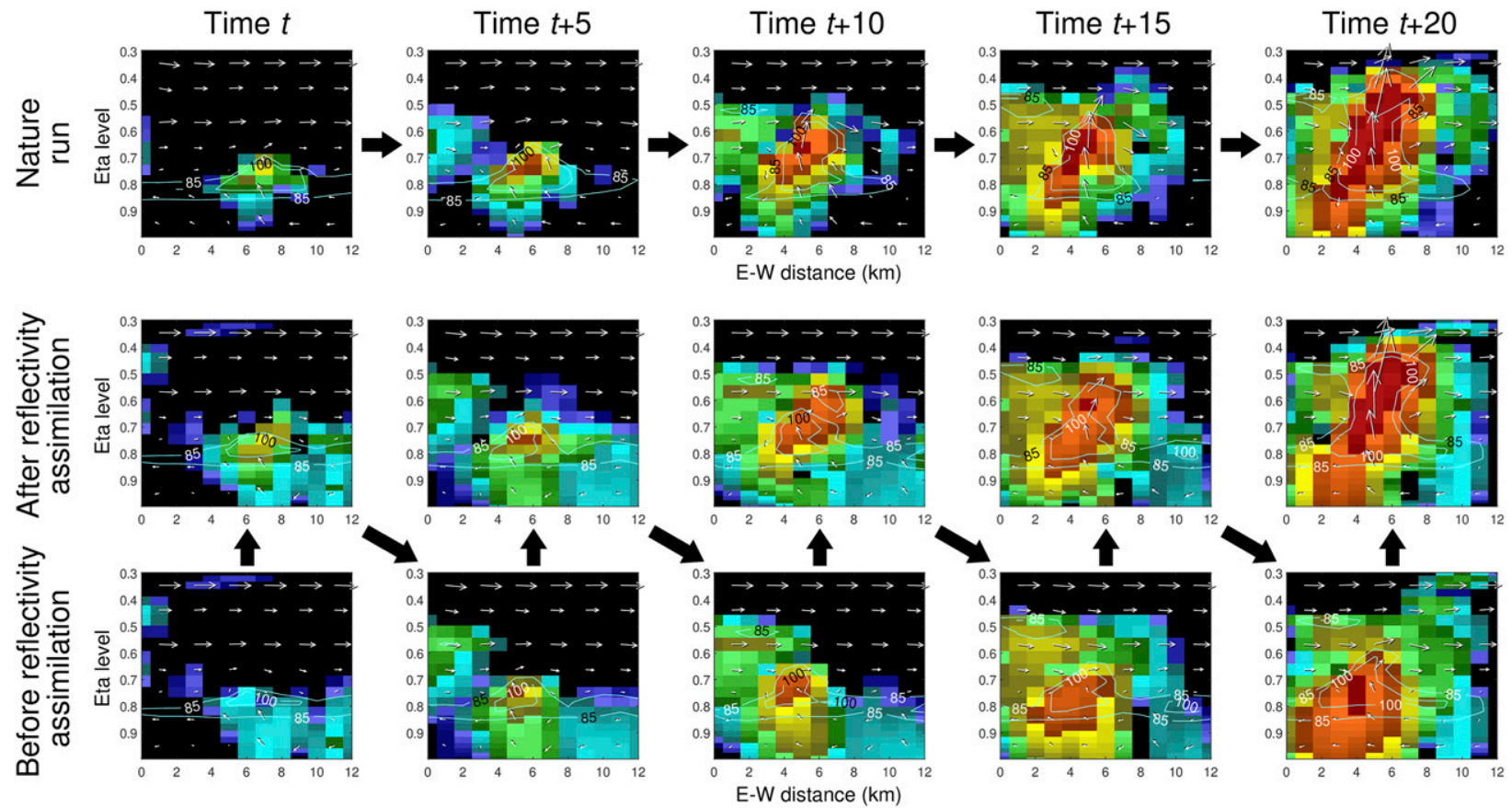

Precipitation mass:

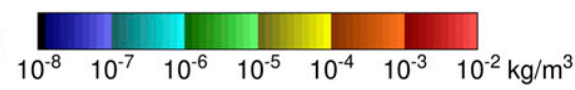

$u-w$ winds: $\stackrel{\uparrow}{\longrightarrow} \mathrm{m} / \mathrm{s}$

RH contours: $85 \%, 100 \%$

FIG. 9. Comparison of the time sequence over 20 min of a "real" growing cell (the nature run of an identical twin experiment) with that of the same cell whose evolution is driven by assimilating reflectivity "data" from the nature run. Each frame represents an east-west cross section of precipitation mass in color and of zonal $(u)$ and vertical $(w)$ winds as vectors, on which are superposed contours of $85 \%$ and $100 \%$ relative humidity in cyan. In the top row, black arrows illustrate the progression of time on the nature run; in the bottom two rows, they indicate the time sequence of the succession between assimilation cycles (up-pointing arrows) followed by the modeling cycles (oblique arrows). While precipitation mass is relatively well assimilated at every step, changes in winds and humidity, among others, are generally insufficient in the bottom half of the troposphere. As a result, the modeled cell is anemic and does not evolve like the real one. Model runs are from Sodhi and Fabry (2020), and the assimilation is based on EAKF under DART and is done with reflectivity data at nine levels every $1 \mathrm{~km}$ horizontally with a $3-\mathrm{km}$ localization window.

time progresses. However, the modeled cell evolves differently, and the repeated assimilation of reflectivity information fails to rectify that behavior: While, at every time step, precipitation is reasonably well corrected by reflectivity data assimilation, changes in dynamical and thermodynamic properties (e.g., winds and humidity) are insufficient in the bottom half of the troposphere. There are many reasons for this problem. One reason that affects wind fields is that, especially at low levels, heavier precipitation is associated with stronger updrafts early in the cell's life cycle, and stronger downdrafts late; as a result, limited net correlation exists between reflectivity and updrafts if members have both growing and mature cells. At higher levels, precipitation and updrafts are generally collocated, hence assimilation performs better there. Another reason that this time affects humidity is that a relative humidity near $100 \%$ can be observed for a wide range of precipitation rates, while much drier conditions occur generally when precipitation is absent. The relationship between humidity and precipitation is hence bilinear on average, increasing rapidly at first at very weak precipitation but stabilizing beyond. Under these conditions, when a single linear relationship between humidity and precipitation is derived by the assimilation system, it leads to undercorrection of humidity in weak precipitation and overcorrection in strong precipitation. For these reasons and others, 1) the lower-level updraft (up to $t+15 \mathrm{~min}$ ) and downdraft $(t+20 \mathrm{~min}$ ) in the precipitation core are not well captured and 2) the air is generally not saturated with humidity where precipitation is added near the top of the cell except at $t+20$ min. Hence, when the model runs, evaporation suppresses the already-weak updraft and precipitation fails to grow sufficiently. In the end, the modeled cell cannot evolve in like the real cell, because it neither flows nor generates precipitation, sensible heat, and latent heat like the real cell. 
TABLE 2. Conditions of success and possible causes of failure of radar data assimilation.

\begin{tabular}{|c|c|}
\hline Conditions of success of data assimilation & Some radar-specific challenges \\
\hline $\begin{array}{l}\text { Observability condition: Measurements can be used to modify } \\
\text { the background if they are able to reveal a mismatch } \\
\text { between simulated and real observations }\end{array}$ & $\begin{array}{l}\text { 1) Operational radars measure a limited number of properties; } \\
\text { 2) over most of the model domain, observations provide no new } \\
\text { information given the absence of both real and simulated echoes }\end{array}$ \\
\hline $\begin{array}{l}\text { Reproducibility condition: The model must have the variables, } \\
\text { physics, and resolution needed to 1) generate the real } \\
\text { current atmospheric state and 2) simulate accurately the } \\
\text { physics of the measurement process }\end{array}$ & $\begin{array}{l}\text { 1) The small-scale processes that shape rainfall and its reflectivity } \\
\text { are often not resolvable; 2) accurate observation simulation is } \\
\text { too complex or impossible given the available information } \\
\text { (e.g., indirectly derived reflectivity, or velocity biases in shear) }\end{array}$ \\
\hline $\begin{array}{l}\text { Error characterization condition: Observations and their } \\
\text { simulation must be statistically unbiased, and their error } \\
\text { covariance must be known }\end{array}$ & $\begin{array}{l}\text { 1) Radar measurements contain artifacts and have poorly } \\
\text { characterized correlated errors; } 2 \text { ) no detectable weather echo } \\
\text { = zero reflectivity; } 3 \text { ) oversimplified observation simulation } \\
\text { adds unknown correlated errors }\end{array}$ \\
\hline $\begin{array}{l}\text { Usability condition: The assimilation system must be able to } \\
\text { use the observation-background mismatch to efficiently } \\
\text { adjust the model state variables affecting the simulated } \\
\text { observation }\end{array}$ & $\begin{array}{l}\text { Especially when reflectivity is assimilated in } \mathrm{dB} Z \text { values, the } \\
\text { relationship between errors in reflectivity and errors in related } \\
\text { state variables such as precipitation mixing ratio is not linear }\end{array}$ \\
\hline $\begin{array}{l}\text { Propagability condition: Innovations in observations can be } \\
\text { propagated to unobserved state variables if usable } \\
\text { relationships between them exist and are known to or } \\
\text { determinable by the assimilation system }\end{array}$ & $\begin{array}{l}\text { Convective patterns have primarily small-scale variability and the } \\
\text { covariance of their error with those of other state variables is } \\
\text { limited, especially at longer distances and in the context of large } \\
\text { background errors }\end{array}$ \\
\hline $\begin{array}{l}\text { Relevance condition: Changed fields must play a significant role } \\
\text { in the future evolution of the weather patterns of interest for } \\
\text { forecasts to be improved }\end{array}$ & $\begin{array}{l}\text { Correcting precipitation has the least impact on the future } \\
\text { outcome of storms; key fields such as temperature and humidity } \\
\text { are harder to modify using radar data }\end{array}$ \\
\hline
\end{tabular}

It will also be unable to correctly interact with neighboring storms, affecting our ability to forecast these storms.

All issues considered, reflecting on the analysis from this section, we surmise that the rapid skill loss observed in precipitation after radar data assimilation (Fig. 1) largely stems from the inability of assimilation systems to correct unobserved fields, including those away from storms. This results from the fact that radar primarily takes measurements in precipitation, a mostly zero-valued field that generally has nonlinear relationships with other state variables, and that largely arises from atmospheric instabilities where errors are large and have limited spatial correlation.

\section{How do we confront these difficulties?}

Radar data assimilation is difficult and prone to failure for a multitude of reasons as summarized in Table 2 . For the foreseeable future, however, it will largely remain all that we have to enable the use of NWP for storm warnings. We must therefore try to make the best of a difficult situation. Doing so requires confronting the challenges specific to radar data assimilation, recognizing that unique problems may require unique solutions.

Although the picture we painted until now may look bleak, we do not believe that the situation is hopeless. For example, many numerical experiments such as Crook (1996) show how small changes in environmental humidity or temperature lead to large changes in precipitation and its patterns. Hence, one should be able to take advantage of that fact to improve our knowledge of the said temperature or humidity. However, this is not well done with current practices (e.g., Fig. 9). In parallel, instabilities often evolve in expectable ways, and this could potentially be exploited. The challenge becomes finding new approaches that account for the strengths and limitations of radar data as well as the nature of the problems we face. Two key goals should be sought in priority: 1) correcting fields far away from precipitation and 2) devising error-reduction methods that work well in the context of large and rapidly growing background uncertainty in atmospherically unstable regions.

We do not know how to successfully face these challenges yet. What follows are a set of possible and complementary avenues of inquiry arising from the issues raised in the previous sections. Several ideas are explored, but the list is far from exhaustive, its purpose being primarily to stimulate reflection.

\section{a. Simpler adjustments to current approaches}

\section{1) REFLECTIVITY INNOVATION AND ERROR RELATIONSHIPS}

We mentioned in section $2 \mathrm{c}(2)$ that measurements of equivalent reflectivity factor $Z_{e}$ are generally assimilated in $\mathrm{dB} Z$ or $\log (Z)$ units. Because $Z_{e}$ and the precipitation rate $R$ from any individual type of precipitation are closely 
linked through a power-law relationship, the previous statement is akin to saying that we are generally assimilating $\log (R)_{\text {radar measurements from radar. Traditional }}$ assimilation systems then estimate or use a linear relationship between errors in $\log (R)_{\text {bkgd }}$ in the background and those in state variables. Once the assimilation system has combined the $\log (R)_{\text {bkgd }}$ and $\log (R)_{\text {radar }}$ to determine a new $\log (R)_{\text {anal }}$ for the analysis, the innovation $\left[\log (R)_{\text {anal }}-\right.$ $\left.\log (R)_{\text {bkgd }}\right]$ is then used to update state variables by $\left[\log (R)_{\text {anal }}-\log (R)_{\text {bkgd }}\right] \Delta$. Assimilating reflectivity in $\mathrm{dB} Z$ units hence leads to the following proportionality relationship: If an innovation $a$ in $\log (R)$ is associated with a state change $a \boldsymbol{\Delta}$, then an innovation $b$ in $\log (R)$ should be associated with a state change $b \boldsymbol{\Delta}$.

Given this assumption, the following example is expected to be true: If a change in rainfall $R$ from 1 to $10 \mathrm{~mm} \mathrm{~h}^{-1}$ [or $\log _{10}(R)$ changing by 1$]$ is associated with an increase in updraft velocity $w$ of $0.3 \mathrm{~ms}^{-1}$, then a change in $R$ from 1 to $100 \mathrm{~mm} \mathrm{~h}^{-1}$ [or $\log _{10}(R)$ changing by 2] leads to an increase in $w$ of $0.6 \mathrm{~m} \mathrm{~s}^{-1}$. At face value, this is ridiculous. We know that, physically, the rate of water vapor condensation is proportional to $w$ and that if the system is in steady state then rainfall must be linearly linked to the rate of condensation and hence to $w$. Changes in $w$ do not scale with changes in $\log (R)$ : While updrafts of $0-0.1$ and $0.3-0.4 \mathrm{~ms}^{-1}$ may sustain rainfalls of 1 and $10 \mathrm{~mm} \mathrm{~h}^{-1}$, respectively, at steady state, an updraft of $0.6-$ $0.7 \mathrm{~m} \mathrm{~s}^{-1}$ will not be sufficient for a $100 \mathrm{~mm} \mathrm{~h}^{-1}$ rainfall. Continuing this example, a rainfall of $0.1 \mathrm{~mm} \mathrm{~h}^{-1}\left[\log _{10}(R)\right.$ changing by -1 ] would then lead to a downdraft of $0.2-$ $0.3 \mathrm{~m} \mathrm{~s}^{-1}$, which is also an unlikely scenario.

These inconsistencies arise because of the assumed linearity between increments in simulated observations and increments in state variables. Here, because assimilated observations are proportional to $\log (R)$, this assumption leads to improbable results. Note that if errors were small, the nonlinearity of the logarithm function would not matter; but since errors are often large, it becomes important.

We are not obliged to assimilate reflectivity as $10 \log _{10}(Z)$. We can take advantage of the fact that, to a first order, $Z \approx a_{Z R} R^{b_{Z R}}$, or also $Z \approx a_{Z q} q_{\text {rain }}^{b_{Z q}}$, to assimilate $Z^{1 / b_{Z R}}$ or $Z^{1 / b_{Z q}}$, quantities roughly proportional to the rainfall $R$ and to the mixing ratio $q_{\text {rain }}$, respectively. Assimilating a transformed measurement would not be unprecedented, as satellite measurements are often assimilated using the transformed quantity brightness temperature $T_{\mathrm{BB}}$, and not as rawer measurements of radiances (e.g., Garand 2003). This is both for reasons of convenience, errors tending to be constant in $T_{\mathrm{BB}}$, and because it leads to near-linear relationships between innovations in $T_{\mathrm{BB}}$ and innovations in wanted properties such as $T$. The main benefit of assimilating a quantity that is roughly proportional to $R$ or $q_{\text {rain }}$ would be its more linear relationship to other state variables.

However, we do not expect errors in all atmospheric properties to be better correlated with errors in precipitation rate or amounts. Errors in humidity for example probably depend more on the presence of enough precipitation than on variations of its intensity. The best unit to use for reflectivity innovation may hence depend on the state variables whose error we wish to reduce.

We can for example contrast the correlation between errors in state variables with 1) errors in rain mass, 2) errors in the logarithm of reflectivity, or 3) errors involving the mere presence or absence of echoes greater than $10 \mathrm{dBZ}$ (Fig. 10). This exercise illustrates that, for some state variables such as precipitation and updrafts, assimilating quantities closely related to rain amounts would lead to better error reduction while, for vapor, assimilating the presence of precipitation echoes does as well as assimilating any richer quantity. Note that this result could have been predicted in advance based on physical reasoning: rain mass is closely related to rain rate, and so is vertical velocity as explained previously. For vapor, the approximately bilinear relationship with precipitation is better fitted by a simple "precipitation" flag where precipitating areas tend to have $100 \%$ humidity while the humidity of nonprecipitating areas stays close to that of the environment. What Fig. 10 illustrates is that using some physically based reasoning, we can determine which relationship should perform better, and use it to our advantage. Here we have limited ourselves to three simple scenarios, but more could be explored.

In parallel, for variables like precipitation that are positive definite and non-Gaussian, ensemble data assimilation approaches that are based on non-Gaussian statistics may also need to be explored (Posselt and Bishop 2018; Anderson 2019).

\section{2) Member Relevance AND CONDitional SELECTION}

The use of more complex relationships between errors in radar-measured quantities and in state variables is actually a timid response to a much more complex problem. Initial background errors are large (Fig. 2). Especially in the context of an atmosphere conditionally unstable for convection, these then grow rapidly, destroying simple error relationships. Figure 11 conceptually illustrates this process: It is not uncommon to have, for any specific grid point, members with no convection, some with growing convection, and some with mature convection. In the absence of echoes, no relationship is expected between echo strength and any state variable; in the growing stages of a cell, updrafts, cloudiness, and temperature positively correlate with 


\section{Correlation between ensemble-simulated errors in some rain properties and in various model state variables}
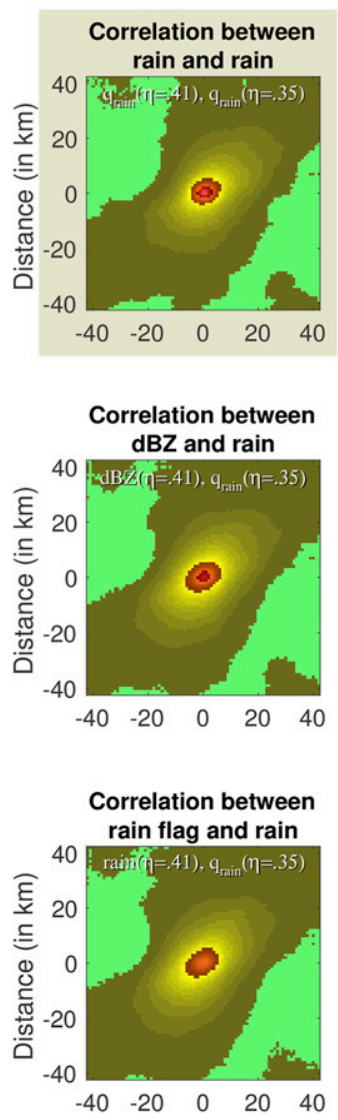
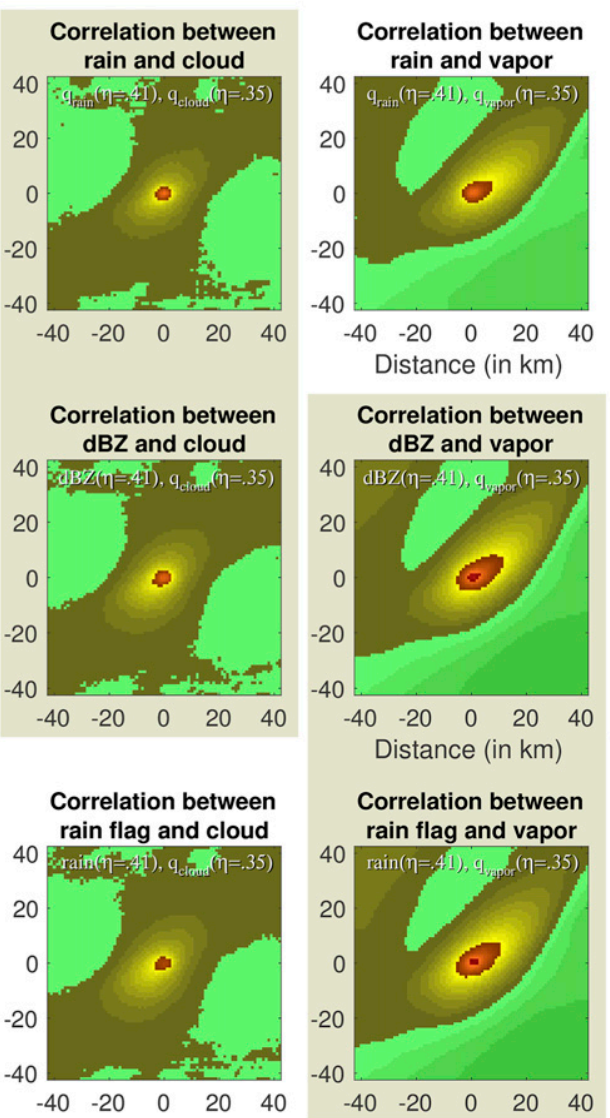
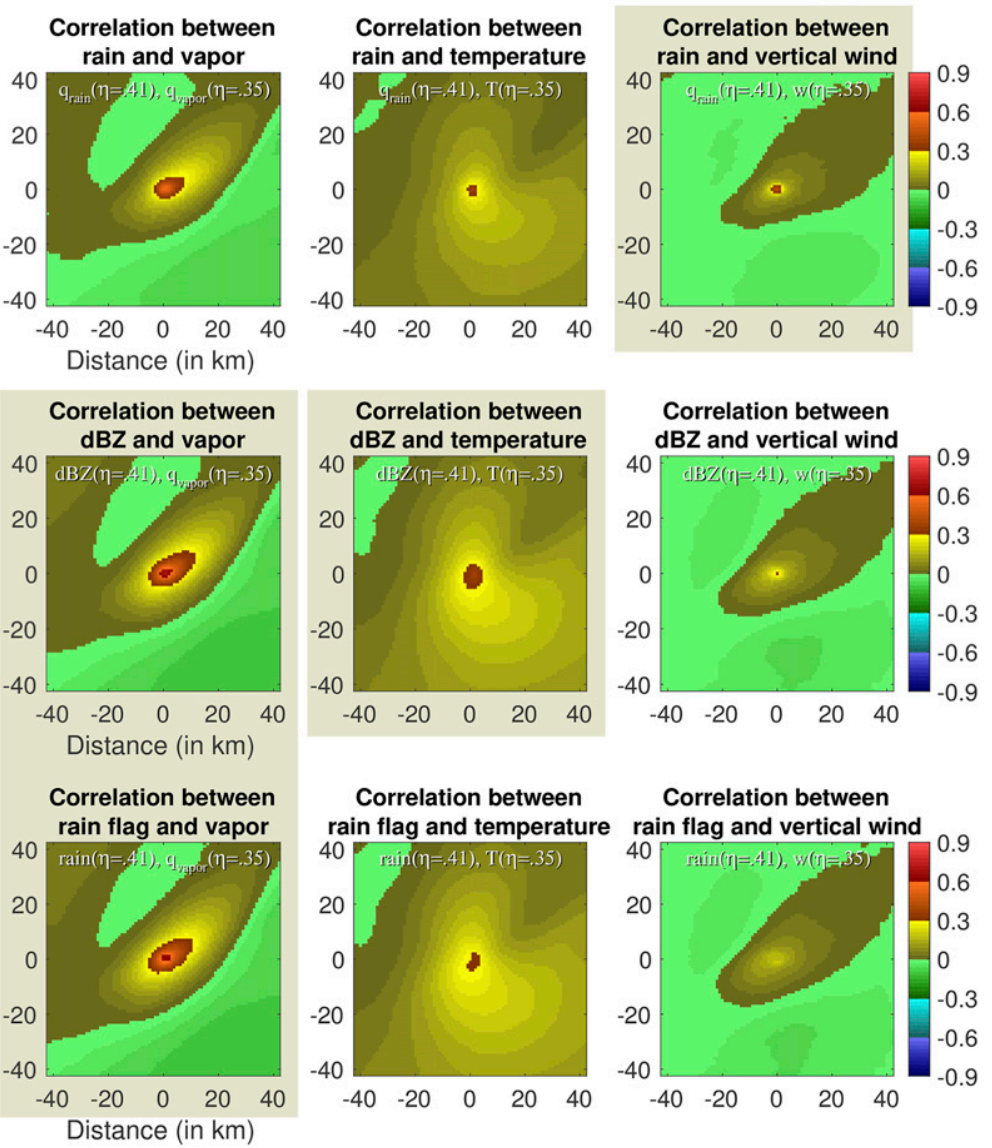
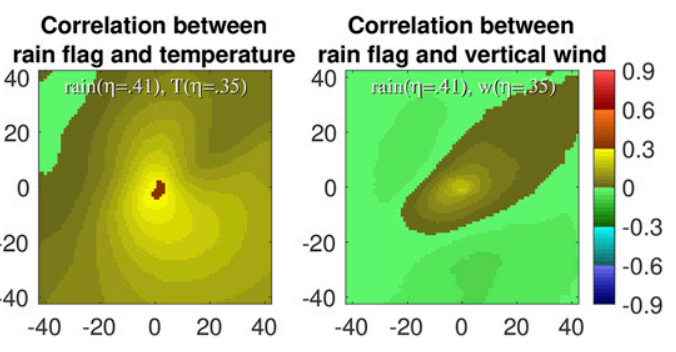

FIG. 10. (top) Average correlation between (top) rain mixing ratio, (middle) simulated reflectivity measurements, or (bottom) a flag of presence of echoes greater than $10 \mathrm{dBZ}$ from the ensemble generated by Jacques and Zawadzki (2015) and nearby background state variables of (left) rain mixing ratio $q_{\mathrm{rain}}$, (left center) cloud mixing ratio $q_{\text {cloud }}$, (center) water vapor mixing ratio $q_{\text {vapor }}$, (right center) temperature $T$, and (right) vertical velocity $w$ in the upper troposphere. Shaded panel backgrounds highlight for which of the three radarderived quantities we observe stronger correlation with each state variable.

echo strength, or maybe with echo intensification; in the mature stage, the opposite occurs, stronger precipitation cores being associated with stronger downdrafts and cold pools. Under such circumstances, any attempt to find a single relationship, however sophisticated, between errors in echo strength and state variables is doomed: If the assimilation system tries to derive unique relationships applicable to all situations, the result will be an odd mixture of all of them. Consequently, error reduction is unlikely to be very effective.

This discussion highlights the importance of meteorological context and how it affects the applicability of expected relationships between observed and unobserved quantities. Context can include meteorological relevance, such as whether the members are in the correct phase of the evolution of the cell. It can also be spatial, such as whether the grid point considered is at the center of the cell, ahead, or behind. In traditional assimilation approaches, this context is assumed to be correct and identical for all members, largely because background errors are small; but when they become large, such an assumption breaks down.

A better approach may be to use simulated and real observations to determine the pertinent context, and then derive a more appropriate relationship accordingly. As a simple example, let us assume that we know from observations that the state variables to be corrected are in the middle of the precipitation core; we can hence repeat the computations done in Fig. 10 but only selecting members where a local reflectivity maximum is within $1 \mathrm{~km}$ of the point of interest. The result, shown in Fig. 12, shows that much higher error covariance can be achieved. This implies that relevant members could be better corrected.

What this leaves out is what to do with the irrelevant members. For those, a very different type of error correction must be considered. In the past, these have included, 


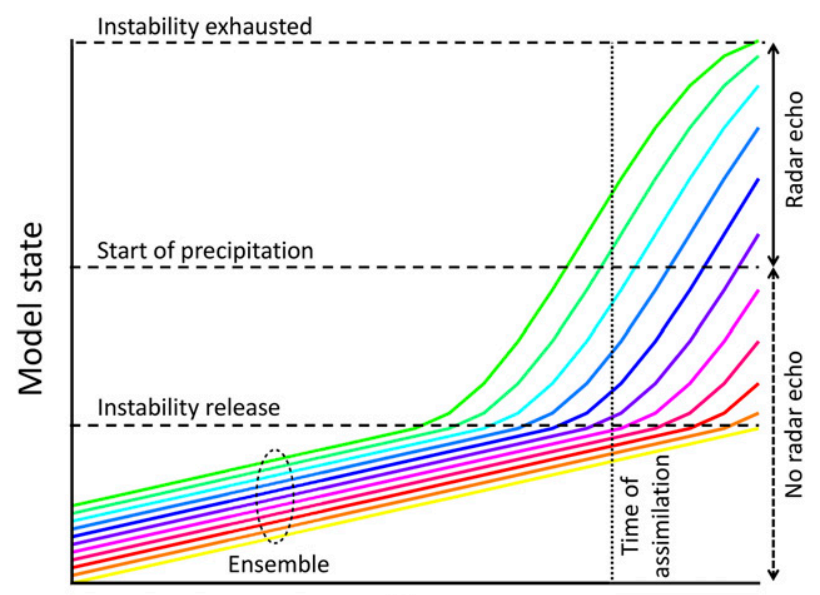

Time

FIG. 11. Illustration of the evolution of the phase state of ensemble members as a function of time as they experience the release of a convective instability at different times. At the annotated time of assimilation, some members (from yellow to red) have not experienced the instability, whereas only a subset of them (in green) have precipitation. The task of the assimilation system is to devise a way to correct the model state from all those members using radar observations given a truth that may lie anywhere within such an ensemble.

among others, moving patterns around (e.g., Brewster 2003a,b; Stratman et al. 2018), adding/suppressing surface heat and column moisture to create/suppress storms using ad hoc processes (e.g., Wattrelot et al. 2014; De Lozar et al. 2018), or correcting them using information from relevant members such as by using localized particle filters (Poterjoy et al. 2017). These and new approaches should be explored more thoroughly.

\section{3) LARGER-SCALE CORRECTIONS}

As seen previously, compared to other fields, precipitation varies considerably at small scales, and proportionally less at larger scales (Fig. 3). As a result, errors in distant atmospheric properties are unlikely to be correlated with errors in point rainfall (Fig. 8). The errors in rainfall at any grid point is instead generally the result of storm displacement errors or morphological differences in the precipitation pattern. But if smaller-scale errors or patterns are filtered, error correlation increases (e.g., Fig. 13). This is partly because rapidly evolving small-scale patterns with large errors are suppressed, and slowly evolving larger-scale patterns with more linear errors can be revealed. Multiscale approaches vary from smoothing background error covariances (e.g., Miyoshi and Kondo 2013; Caron and Buehner 2018) to smoothing observations (Sodhi and Fabry 2020). While spatial smoothing of covariances and of observations are being explored, so could temporal smoothing. By effectively smoothing error patterns, both approaches allow the use of much larger localization windows that increase the projection of information. Here too, other ideas would be welcome.

\section{b. Diversifying approaches}

The ideas proposed above can largely be implemented within traditional adjustment-based assimilation systems. But to better tackle the challenges posed by both limited information propagation and the large background errors, radically different approaches may have to be considered. We believe for example that the time evolution and the spatial structure of echo patterns are not well exploited in convective-scale assimilation, yet could provide valuable information. When one only has synoptic point data, all one can rely on is error covariance. But when data are available everywhere and all the time, derived quantities can conceivably be exploited such as the position and strength of key features (reflectivity cores, low-level radial divergence, tropospheric-wide velocity couplets, etc.). For example, vertical velocity may be better related with precipitation tendencies than with the precipitation rate itself (Haddad et al. 2018). In parallel, we should also better take advantage of additional

\section{Error correlation with state variables contingent on being close to a local reflectivity maximum}
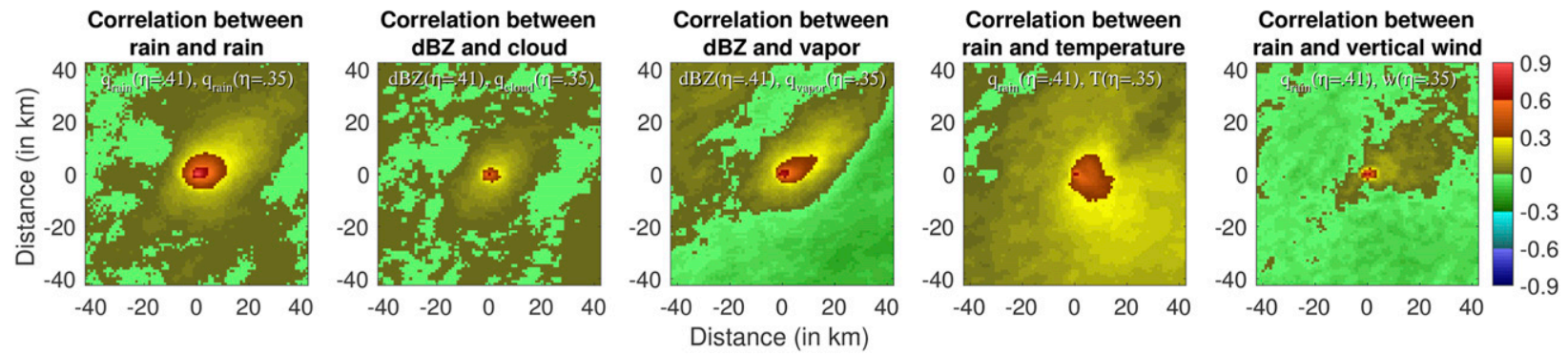

FIG. 12. Average correlation between either rain mixing ratio ("rain") or simulated reflectivity measurements ("dBZ") from the ensemble generated by Jacques and Zawadzki (2015) and nearby background state variables of (left) $q_{\text {rain }}$, (left center) $q_{\text {cloud }}$, (center) $q_{\text {vapor, }}$ (right center) $T$, and (right) $w$ in the upper troposphere. As opposed to Fig. 10, average error correlations in excess of 0.6 can be observed for all of these background variables. 

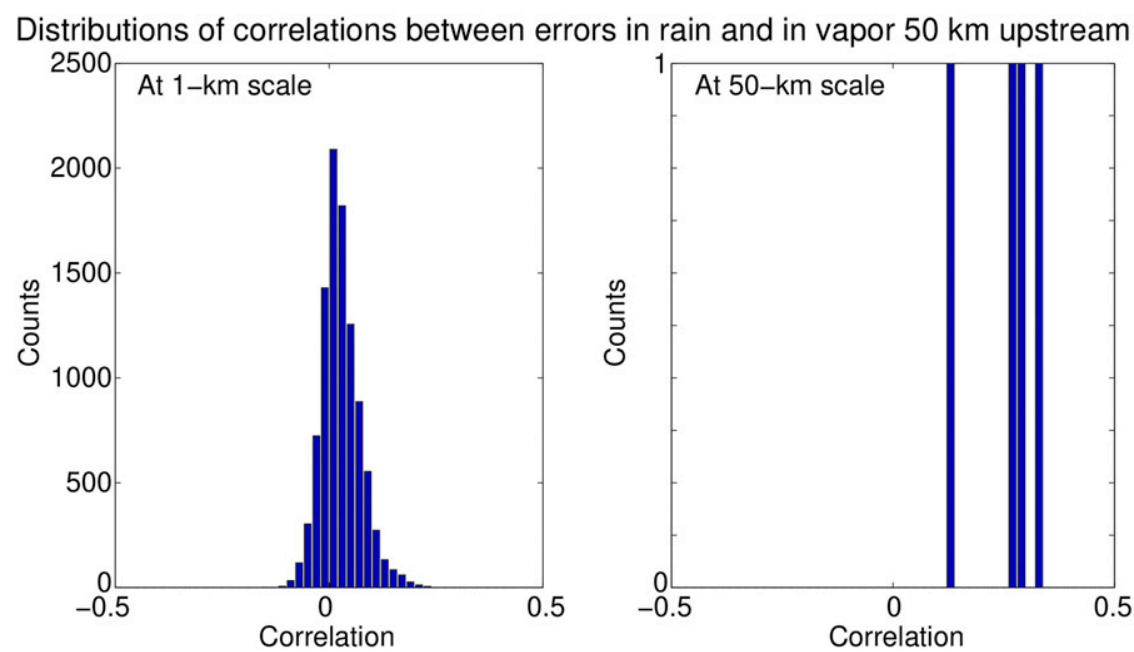

FIG. 13. Distribution of correlations at 1-km altitude between errors in rain mass and in vapor amounts $50 \mathrm{~km}$ to the east of the rain for the ensemble generated by Jacques and Zawadzki (2015). Shown are correlations of (left) $1 \mathrm{~km} \times 1 \mathrm{~km}$ scale values and (right) $50 \mathrm{~km} \times 50 \mathrm{~km}$ averages. As state variables and observations are smoothed, error correlation increases.

radar and remotely sensed measurements to help better constrain storms as well as their environments. We believe that traditionally assimilated radar data do not provide enough variety of constraints to effectively reduce background errors.

Perhaps should we also embrace the information provided by instability releases. The atmosphere is unpredictable because of instabilities, and precipitation generally occurs in the middle or final stages of the release of atmospheric instabilities. Paradoxically, we rarely have a better constraint on the state of the atmosphere than at the instant an instability is being triggered, as conditions for their triggering are often very specific. Therefore, the instability triggering event itself is a powerful piece of information if it could be intelligently taken advantage of. This would be in addition to making use of the information of the past consequences of a storm, as is done for example with latent heat nudging.

Then, to deal with large errors at the assimilation level, more heuristic methods may have to be explored. For example, Pérez Hortal et al. (2019) constructed analyses by selecting, for each vertical column in the model, the ensemble member whose areal precipitation is locally closest to the observed values. Variations on particle filters may also be possible, among others, to eliminate members whose errors became so large that their information turns out to be misleading.

\section{c. Parting words}

Radar data assimilation is fraught with dataset-specific challenges (Table 2). There hence does not appear to be any single solution that will transformatively improve its skill. Each advance will only bring us a bit closer to success, but a wise colleague of ours keeps repeating "I'll take a few percent of something over 100\% of nothing any day" (G. McCourt, 2010-19, personal communication). It is only via considerable efforts that radar data assimilation can substantially help in improving convective-scale NWP. And for the foreseeable future, only the proper assimilation of radar and other remotely sensed data can enable the skillful forecasting of convective weather by NWP.

Acknowledgments. Heartfelt thanks are given to Isztar Zawadzki who encouraged the first author to write this paper. The authors acknowledge the help of Andrés Pérez Hortal for the introduction and of Dominik Jacques and Jagdeep Singh Sodhi for their ensemble forecast data. This project was undertaken with the financial support of the Government of Canada provided through the Department of the Environment through Grants and Contributions GCXE16S123. This work is also partly based on TIGGE data. The THORPEX Interactive Grand Global Ensemble (TIGGE; Bougeault et al. 2010) is an initiative of the World Weather Research Programme (WWRP). Last, this research was enabled in part by support provided by Calcul Québec (https://www.calculquebec.ca) and Compute Canada (https://www.computecanada.ca).

\section{REFERENCES}

Aksoy, A., D. C. Dowell, and C. Snyder, 2010: A multicase comparative assessment of the ensemble Kalman filter for assimilation of radar observations. Part II: Short-range ensemble forecasts. Mon. Wea. Rev., 138, 1273-1292, https://doi.org/ 10.1175/2009MWR3086.1. 
Anderson, J., 2019: A nonlinear rank regression method for ensemble Kalman Filter data assimilation. Mon. Wea. Rev., 147, 2847-2860, https://doi.org/10.1175/MWR-D-18-0448.1.

—, T. Hoar, K. Raeder, H. Liu, N. Collins, R. Torn, and A. Avellano, 2009: The Data Assimilation Research Testbed: A community facility. Bull. Amer. Meteor. Soc., 90, 1283-1296, https://doi.org/10.1175/2009BAMS2618.1.

Augros, C., O. Caumont, V. Ducrocq, and N. Gaussiat, 2018: Assimilation of radar dual-polarization observations in the AROME model. Quart. J. Roy. Meteor. Soc., 144, 1352-1368, https://doi.org/10.1002/qj.3269.

Benjamin, S. G., and Coauthors, 2016: A North American hourly assimilation and model forecast cycle: The Rapid Refresh Mon. Wea. Rev., 144, 1669-1694, https://doi.org/10.1175/ MWR-D-15-0242.1.

Bougeault, P., and Coauthors, 2010: The THORPEX Interactive Grand Global Ensemble. Bull. Amer. Meteor. Soc., 91, 1059-1072, https://doi.org/10.1175/2010BAMS2853.1.

Brewster, K. A., 2003a: Phase-correcting data assimilation and application to storm-scale numerical weather prediction. Part I: Method description and simulation testing. Mon. Wea. Rev., 131, 480-492, https://doi.org/10.1175/1520-0493(2003) $131<0480:$ PCDAAA $>2.0$. CO 2 .

- 2003b: Phase-correcting data assimilation and application to storm-scale numerical weather prediction. Part II: Application to a severe storm outbreak. Mon. Wea. Rev., 131, 493-507, https:// doi.org/10.1175/1520-0493(2003)131<0493:PCDAAA > 2.0.CO;2

Caron, J.-F., and M. Buehner, 2018: Scale-dependent background error covariance localization: Evaluation in a global deterministic weather forecasting system. Mon. Wea. Rev., 146, 1367-1381, https://doi.org/10.1175/MWR-D-17-0369.1.

Crook, N. A., 1996: Sensitivity of moist convection forced by boundary layer processes to low-level thermodynamic fields. Mon. Wea. Rev., 124, 1767-1785, https://doi.org/10.1175/15200493(1996)124<1767:SOMCFB > 2.0.CO;2.

De Lozar, A., A. Seifert, and U. Blahak, 2018: Direct assimilation of 3D radar reflectivities with an ensemble-based data assimilation system. Sixth Int. Symp. on Data Assimilation, Munich, Germany, Deutscher Wetterdienst, 2.2, https:// isda2018.wavestoweather.de/program/radar-d-a-and-nowcasting/ o2_2_delozar.pdf.

Dowell, D. C., L. J. Wicker, and C. Snyder, 2011: Ensemble Kalman filter assimilation of radar observations of the 8 May 2003 Oklahoma City supercell: Influences of reflectivity observations on storm-scale analyses. Mon. Wea. Rev., 139, 272-294, https://doi.org/10.1175/2010MWR3438.1.

Errico, R. M., P. Bauer, and J.-F. Mahfouf, 2007: Issues regarding the assimilation of cloud and precipitation data. J. Atmos. Sci., 64, 3785-3798, https://doi.org/10.1175/2006JAS2044.1.

Fabry, F., 2010: Radial velocity measurement simulations: Common errors, approximations, or omissions and their impact on estimation accuracy. Proc. Sixth European Conf. on Radar in Meteorology and Hydrology, Sibiu, Romania, ERAD, 17.2, http://www.erad2010.com/pdf/oral/thursday/ nwp1/02_ERAD2010_0154.pdf.

_ 2015: Radar Meteorology_Principles and Practice. Cambridge University Press, 272 pp.

Garand, L., 2003: Toward an integrated land-ocean surface skin temperature analysis from the variational assimilation of infrared radiances. J. Appl. Meteor., 42, 570-583, https://doi.org/ 10.1175/1520-0450(2003)042<0570:TAILSS > 2.0.CO;2.

Gastaldo, T., V. Poli, C. Marsigli, P. P. Alberoni, and T. Paccagnella, 2018: Data assimilation of radar reflectivity volumes in a
LETKF scheme. Nonlinear Processes Geophys., 25, 747-764, https://doi.org/10.5194/npg-25-747-2018.

Germann, U., and I. Zawadzki, 2002: Scale-dependence of the predictability of precipitation from continental radar images. Part I: Description of the methodology. Mon. Wea. Rev., 130, 2859-2873, https://doi.org/10.1175/1520-0493(2002)130<2859: $\mathrm{SDOTPO}>2.0 . \mathrm{CO} ; 2$.

Gustafsson, N., and Coauthors, 2018: Survey of data assimilation methods for convective-scale numerical weather prediction at operational centres. Quart. J. Roy. Meteor. Soc., 144, 1218-1256, https://doi.org/10.1002/qj.3179.

Haddad, Z. S., O. O. Sy, G. L. Stephens, S. C. van den Heever, and D. J. Posselt, 2018: Atmospheric remote sensing with convoys of miniature radars. Proc. SPIE, 10776, 1077601, https:// doi.org/10.1117/12.2500285.

Jacques, D., and I. Zawadzki, 2015: The impacts of representing the correlation of errors in radar data assimilation. Part II: Model output as background estimates. Mon. Wea. Rev., 143, 2637-2656, https://doi.org/10.1175/MWR-D-14-00243.1.

, D. Michelson, J.-F. Caron, and L. Fillion, 2018: Latent heat nudging in the Canadian regional deterministic prediction system. Mon. Wea. Rev., 146, 3995-4014, https://doi.org/ 10.1175/MWR-D-18-0118.1.

Jones, T. A., D. Stensrud, L. Wicker, P. Minnis, and R. Palikonda, 2015: Simultaneous radar and satellite data storm-scale assimilation using an ensemble Kalman filter approach for 24 May 2011. Mon. Wea. Rev., 143, 165-194, https://doi.org/ 10.1175/MWR-D-14-00180.1.

Kalnay, E., and S.-C. Yang, 2010: Accelerating the spin-up of ensemble Kalman filtering. Quart. J. Roy. Meteor. Soc., 136, 1644-1651, https://doi.org/10.1002/qj.652.

Keeler, R. J., and R. E. Passarelli, 1990: Signal processing for atmospheric radars. Radar in Meteorology, D. Atlas, Ed., Amer. Meteor. Soc., 199-229.

_- - and S. M. Ellis, 2000: Observational error covariance matrices for radar data assimilation. Phys. Chem. Earth B Hydrol. Oceans Atmos., 25, 1277-1280, https://doi.org/10.1016/ S1464-1909(00)00193-3.

Knight, C. A., W. D. Hall, and P. M. Roskowski, 1983: Visual cloud histories related to first radar echo formation in northeast Colorado cumulus. J. Climate Appl. Meteor., 22, 1022-1040, https://doi.org/10.1175/1520-0450(1983)022\% 3C1022:VCHRTF\%3E2.0.CO;2.

Kwon, I., S. English, W. Bell, R. Potthast, A. Collard, and B. Ruston, 2018: Assessment of progress and status of data assimilation in numerical weather prediction. Bull. Amer. Meteor. Soc., 99, ES75-ES79, https://doi.org/10.1175/ BAMS-D-17-0266.1.

Lee, G. W., A. W. Seed, and I. Zawadzki, 2007: Modeling the variability of drop size distributions in space and time. J. Appl. Meteor. Climatol., 46, 742-756, https://doi.org/ 10.1175/JAM2505.1.

Li, X., J. R. Mecikalski, and D. Posselt, 2017: An ice-phase microphysics forward model and preliminary results of polarimetric radar data assimilation. Mon. Wea. Rev., 145, 683-708, https://doi.org/10.1175/MWR-D-16-0035.1.

Mandapaka, P. V., U. Germann, L. Panziera, and A. Hering, 2012: Can Lagrangian extrapolation of radar fields be used for precipitation nowcasting over complex alpine orography? Wea. Forecasting, 27, 28-49, https://doi.org/10.1175/ WAF-D-11-00050.1.

Markowski, P., and Y. Richardson, 2010: Mesoscale Meteorology in Midlatitudes. Wiley-Blackwell, 430 pp. 
Miyoshi, T., and K. Kondo, 2013: A multi-scale localization approach to an ensemble Kalman filter. SOLA, 9, 170-173, https://doi.org/10.2151/SOLA.2013-038.

Murakami, M., 1990: Numerical modeling of dynamical and microphysical evolution of an isolated convective cloud. J. Meteor. Soc. Japan, 68, 107-128, https://doi.org/10.2151/ jmsj1965.68.2_107.

Pérez Hortal, A. A., I. Zawadzki, and M. K. Yau, 2019: A heuristic approach for precipitation data assimilation: Characterization using OSSEs. Mon. Wea. Rev., 147, 3445-3466, https://doi.org/ 10.1175/MWR-D-19-0034.1.

Posselt, D. J., and C. H. Bishop, 2018: Nonlinear data assimilation for clouds and precipitation using a gamma-inverse gamma ensemble filter. Quart. J. Roy. Meteor. Soc., 144, 2331-2349, https://doi.org/10.1002/qj.3374.

- X. Li, S. Tushaus, and J. Mecikalski, 2015: Assimilation of dual-polarization radar observations in mixed- and ice-phase regions of convective storms: Information content and forward model errors. Mon. Wea. Rev., 143, 2611-2636, https:// doi.org/10.1175/MWR-D-14-00347.1.

Poterjoy, J., R. A. Sobash, and J. L. Anderson, 2017: Convective-scale data assimilation for the Weather Research and Forecasting Model using the local particle filter. Mon. Wea. Rev., 145, 1897-1918, https://doi.org/10.1175/MWR-D-16-0298.1.

Sodhi, J. S., and F. Fabry, 2020: Multiscale assimilation of radar reflectivity. 24th Conf. on Integrated Observing and Assimilation Systems for the Atmosphere, Oceans, and Land Surface (IOAS-AOLS), Boston, MA, Amer. Meteor. Soc., 4A.4, https://ams.confex.com/ams/2020Annual/meetingapp.cgi/ Paper/363970.

Stensrud, D. J., and Coauthors, 2009: Convective-scale Warn-onForecast system. Bull. Amer. Meteor. Soc., 90, 1487-1500, https://doi.org/10.1175/2009BAMS2795.1.

—_ and Coauthors, 2013: Progress and challenges with Warnon-Forecast. Atmos. Res., 123, 2-16, https://doi.org/10.1016/ j.atmosres.2012.04.004.
Stratman, D. R., C. K. Potvin, and L. J. Wicker, 2018: Correcting storm displacement errors in ensembles using the feature alignment technique (FAT). Mon. Wea. Rev., 146, 2125-2145, https://doi.org/10.1175/MWR-D-17-0357.1.

Sun, J., and Coauthors, 2014: Use of NWP for nowcasting convective precipitation: Recent progress and challenges. Bull. Amer. Meteor. Soc., 95, 409-426, https://doi.org/10.1175/ BAMS-D-11-00263.1.

Supinie, T. A., N. Yussouf, Y. Jung, M. Xue, J. Cheng, and S. Wang, 2017: Comparison of the analyses and forecasts of a tornadic supercell storm from assimilating phased-array radar and WSR-88D observations. Wea. Forecasting, 32, 1379-1401, https://doi.org/10.1175/WAF-D-16-0159.1.

Surcel, M., I. Zawadzki, and M. K. Yau, 2015: A study on the scale dependence of the predictability of precipitation patterns. J. Atmos. Sci., 72, 216-235, https://doi.org/10.1175/JAS-D-14-0071.1.

Tong, M., and M. Xue, 2005: Ensemble Kalman filter assimilation of Doppler radar data with a compressible nonhydrostatic model: OSS experiments. Mon. Wea. Rev., 133, 1789-1807, https://doi.org/10.1175/MWR2898.1.

Wattrelot, E., O. Caumont, and J. Mahfouf, 2014: Operational implementation of the 1D+3D-Var assimilation method of radar reflectivity data in the AROME model. Mon. Wea. Rev., 142, 1852-1873, https://doi.org/10.1175/MWR-D-13-00230.1.

Xue, M., and Coauthors, 2008: CAPS realtime storm-scale ensemble and high-resolution forecasts as part of the NOAA Hazardous Weather Testbed 2008 spring experiment. Preprints, 24th Conf. on Severe Local Storms, Savannah, GA, Amer. Meteor. Soc., 12.2, https://ams.confex.com/ams/24SLS/techprogram/ paper_142036.htm.

Yano, J.-I., and Coauthors, 2018: Scientific challenges of convectivescale numerical weather prediction. Bull. Amer. Meteor. Soc., 99, 699-710, https://doi.org/10.1175/BAMS-D-17-0125.1.

Zrnić, D. S., 1979: Estimation of spectral moments for weather echoes. IEEE Trans. Geosci. Electron., 17, 113-128, https:// doi.org/10.1109/TGE.1979.294638. 